ISSN: $1130-2887$

\title{
POLÍTICA EXTERIOR DE LOS EE.UU. HACIA COLOMBIA: EL PAQUETE DE AYUDA DE 1.300 MILLONES DE DÓLARES DE APOYO AL PLAN COLOMBIA Y LA REGIÓN ANDINA U.S. foreign policy towards Colombia: the $\$ 1.3$ billion aid package to support Plan Colombia and the Andean Region
}

\author{
Borja DíAZ RIVILLAS \\ Universidad de Salamanca \\ 凶bdiaz@usal.es
}

BIBLID [1130-2887 (2002) 31, 145-186]

Fecha de recepción: mayo de 2002

Fecha de aceptación y versión final: julio de 2002

RESUMEN: El final del segundo mandato del presidente Bill Clinton supuso un cambio importante en la estrategia de los EE.UU. hacia el conflicto armado colombiano. Washington dejó de apoyar el proceso de paz, y pasó a tener un enfoque más belicista, que culminó con la aprobación por parte del Congreso de un paquete de ayuda de 1.300 millones de dólares con un alto componente militar en el presupuesto suplementario del 2000, como apoyo al Plan Colombia de Andrés Pastrana y a la región andina.

En la primera parte del presente texto se analizan los cambios y continuidades acontecidos en la política exterior de los EE.UU. hacia América Latina tras el final de la Guerra Fría y la evolución de las relaciones bilaterales entre Colombia y los EE.UU. En la segunda se exponen los motivos que llevaron a Clinton a incluir el asunto en su agenda política y a solicitar la ayuda al Congreso, y qué instituciones, grupos y personalidades jugaron un papel significativo en el diseño y en la aprobación del paquete de ayuda. Se argumenta que la apertura de la ventana para semejante cambio fue el fruto de la confluencia en el tiempo del recrudecimiento de los problemas de Colombia, de los cambios en la opinión pública estadounidense en vísperas de un cambio de Administración y de las campañas de los grupos de interés. Estos aspectos fueron aprovechados por determinados emprendedores políticos para hacer valer sus soluciones. Se concluye que la aprobación de la ayuda evidencia dos aspectos fundamentales: 1) el interés de los EE.UU. por acabar con grupos insurgentes desestabilizadores para sus intereses y cómo estas intenciones se encubren bajo «la guerra contra las drogas»; 2) los intereses políticos domésticos siguen condicionando las estrategias antinarcóticos en los países productores y pese al fracaso de las acciones centradas en 
el lado de la oferta, la clase política estadounidense persiste en culpar a Colombia del fuerte consumo de drogas en los EE.UU., para evitar así afrontar responsabilidades políticas.

Palabras clave: narcotráfico, Plan Colombia, guerrilla, narcoguerrilla, política exterior estadounidense, política anti-narcóticos.

ABSTRACT: An important change in the U.S. strategy towards the Colombian armed conflict took place at the end of president's Clinton second tenure. Washington ended its support to the peace process and shifted its policy to a militaristic approach that culminated in the approval of an aid package worth $\$ 1.300$ million with a strong military component in the 2000 supplemental budget to back Andres Pastrana's Plan Colombia and the Andean Region.

In the first part of the article and in order to understand the environment in which the aid was granted, the paper analyses the changes and continuities in U.S. foreign policy towards Latin America in the aftermath of the Cold War as well as the evolution of U.S.Colombian bilateral relations. In the second part, I point out the reasons behind Clinton's inclusion of this issue in his political agenda and his request to Congress. I also explore the role that institutions, groups and individuals played in the design and the approval of the aid package. I argue that the opening of a window opportunity for such a change was the result of the worsening of Colombian problems, changes in U.S. public opinion on the eve of a change of Administration and interest group campaigns. Some political entrepreneurs took advantage of these events to push for their solutions.

I conclude that the approval of the aid package shows two relevant factors: 1) U.S. interest in undermining insurgent groups seem as destabilizing for their interests and how these policies are presented as «drug war» initiatives; 2) domestic political interests still determine anti-narcotic strategies in producer countries in spite of the lack of success of anti-drug initiatives on the supply side and U.S. politicians persist on blaming Colombia for the high drug consumption in the U.S. to avoid confronting domestic political responsibilities

Key words: narcotraffic, Plan Colombia, guerrilla, narcoguerrilla, U.S. foreig policy, anti-narcotics policy.

\section{INTRODUCCIÓN: CAMBIOS Y CONTINUIDADES. EL PROCESO DE ELABORACIÓN DE LA POLÍTICA EXTERIOR ESTADOUNIDENSE TRAS EL FINAL DE LA GUERRA FrÍA*}

Tras el final de la Guerra Fría y, pese a la ausencia del desafío económico, ideológico y militar soviético, América Latina ha seguido conservando gran parte de su importancia económica y geopolítica para los EE.UU. La firma del NAFTA (North American Free Trade Agreement) y los esfuerzos por lograr su ampliación a todo el hemisferio a través del ALCA (Área de Libre Comercio de las Américas), la invasión de Panamá y Haití, la continuación del embargo cubano y el creciente aumento de la ayuda militar

* El autor agradece los comentarios que los dos colaboradores anónimos realizaron a este trabajo. 
destinada a la guerra contra las drogas reflejan el peso de la región en la agenda política de Washington.

Si Ronald Reagan (1981-1989) ganó la Guerra Fría y George Bush (1988-1992) llevó a cabo la transición entre una época y otra, a Bill Clinton (1992-2000) le correspondió inaugurar un nuevo orden mundial bajo la hegemonía de los EE.UU. El nuevo orden presenta importantes continuidades y rupturas respecto a los principios de la etapa anterior. A pesar de la ausencia soviética, los EE.UU. se han mantenido como garantes de la estabilidad política y económica en América Latina, si bien esta última faceta la desarrollan en colaboración con los organismos financieros multilaterales.

Durante la Guerra Fría la política exterior de los EE.UU. hacia América Latina estuvo condicionada por la competencia entre las dos grandes superpotencias, por la defensa de los intereses económicos estadounidenses y por consideraciones ideológicas de oposición al comunismo, que hacían que Washington prestara poca atención a la naturaleza autoritaria de muchos regímenes siempre y cuando éstos respaldaran sus intereses.

En el nuevo marco de relaciones con América Latina, el modelo de democracia liberal pasó a ser un elemento mucho más aceptado por su gran impacto en el desarrollo social y económico, por su contribución a la estabilidad y por motivos idealistas. Así lo demuestra la oposición estadounidense a los golpes de Estado en Venezuela (1992), Guatemala (1992) y Paraguay (1996), en los incrementos en los fondos de las agencias estadounidenses para la promoción de la democracia y en la intervención en Haití para restaurar la democracia en cooperación con la Organización de Estados Americanos (OEA).

Clinton proclamó una nueva política exterior hacia América Latina basada en la defensa del libre comercio, de la democracia y de los derechos humanos y en el apoyo a los procesos de paz en los países con grupos insurgentes operando. Tanto él como Madelein F. Albright se disculparon además por el papel de los EE.UU. en Guatemala y en el Cono Sur, y se llevó a cabo la desclasificación de documentos secretos sobre la dictadura chilena (Doyle e Isacson, 2001).

Si bien se ha producido un cambio notable, la promoción de la democracia presenta dos contradicciones muy significativas. Por un lado, la definición de democracia aceptada por los EE.UU. puede llegar a ser sumamente minimalista. Prueba de ello fue el apoyo que Washington dispensó al régimen autoritario con fachada democrática de Alberto Fujimori, con quien se fue permisivo como pago a su éxito en acabar con los grupos insurgentes Sendero Luminoso y Movimiento Revolucionario Túpac Amaru (MRTA), por su eficacia contra el narcotráfico y por haber logrado la estabilidad política y económica necesaria para la inversión extranjera en el país andino.

Por otra parte, pese a que la mayoría de los países de la región cuentan con democracias de tipo electoral, que han adoptado el neoliberalismo y abierto sus mercados a la inversión extranjera, la ayuda y cooperación con los militares de América Latina continua siendo un importante objetivo para Washington. La doctrina de seguridad surgida a raíz de la Revolución Cubana, que permitía las labores de contrainsurgencia para frenar el desarrollo de ideologías comunistas o socialistas incluso en los casos en los que no existiera una amenaza soviética directa, quedó sin justificación. Una de las tareas de Clinton durante su presidencia fue, en consecuencia, redefinir el papel del 
Ejército estadounidense en América Latina, así como su marco de cooperación con los militares de los países de la región.

El principal objetivo de la doctrina de seguridad nacional en el nuevo orden es asegurar la hegemonía política y económica de los EE.UU. en América Latina. Para ello, una de las prioridades del Pentágono es ayudar a los países a solucionar problemas domésticos que amenazan sus intereses y que generan inestabilidad regional. Aunque la ayuda militar en dólares declinó durante un tiempo, los programas de entrenamiento militar, las maniobras y el despliegue de fuerzas especiales por todo el hemisferio, con la excepción de Cuba, siguieron proliferando (Doyle e Isacson, 2001). De este modo y en detrimento de los poderes civiles, se pasó a promocionar una creciente participación de los militares de la región en la confrontación de amenazas no estatales de tipo global, tales como el tráfico de drogas, el terrorismo, los conflictos sociales, la inmigración ilegal, etc. (McSherry, 2000).

Entre 1996 y 1997, a través de la ayuda exterior, la ayuda a los militares y a la policía en América Latina se cuadruplicó (Youngers, 1997) y el despliegue de tropas para misiones especiales se fue también incrementando de forma sostenida. Según el Latin American Working Group con sede en Washington, alrededor de 56.000 soldados de las de tropas especiales estadounidenses circularon por América Latina en el año fiscal 19971. Estos aumentos coincidieron con el levantamiento de la prohibición de ayuda directa a los militares peruanos (vigente desde 1992), así como con las restricciones a los militares colombianos que habían imperado en los años previos por haber estado ambos cuerpos involucrados en serias violaciones de los derechos humanos (Youngers, 1997). En 1999, enviados estadounidenses llevaron a cabo el entrenamiento de 13.000 soldados y policías de América Latina y el número de despliegues de fuerzas especiales ha pasado de 147 en 1995 a cerca de 200 en la actualidad (McSherry, 2000).

La culminación de esta tendencia tuvo lugar con la aprobación por parte del Congreso en el año 2000 de un paquete de ayudas de 1.300 millones de dólares con un alto componente militar de apoyo al Plan Colombia y a la región andina y que supuso el mayor paquete de ayudas a un país de la región desde el final de la Guerra Fría. Por primera vez desde antes de la Alianza por el Progreso de Kennedy, la ayuda militar a América Latina superó a la económica (Doyle e Isacson, 2001).

Estos aumentos indican que tras la desaparición de Sendero Luminoso y el MRTA, la estabilización del conflicto de Chiapas y la firma de los Acuerdos de Paz en Centro América, el conflicto armado colombiano y la lucha contra el narcotráfico en la región andina se consolidaron como el principal foco de inestabilidad regional y como la principal preocupación para Washington en su papel de estabilizador hegemónico.

Así, durante el segundo mandato Clinton el narcotráfico en la región andina y especialmente en Colombia se afianzaron como el nuevo epicentro hacia el que orientar la ayuda y el entrenamiento militar estadounidense.

1. Douglas Farah. A Tutor to Every Army in Latin America. The Washington Post Foreign Service, lunes 13 de julio de 1998. 
Pese a estos hechos, los promotores de esta política han tenido que sortear la falta de consenso existente tras el final de la Guerra Fría entre la opinión pública y la clase política estadounidense sobre los límites en la participación de los EE.UU. en América Latina.

Ya en la última etapa de la Guerra Fría, y a raíz del envío de armas a la contra nicaragüense incumpliendo la prohibición del Congreso, aumentó el recelo del Legislativo y de la opinión pública hacia la Casa Blanca. De igual manera, el Congreso y la opinión pública comenzaron a mirar minuciosamente cualquier actividad militar contrainsurgente que pudiera desembocar en un nuevo Vietnam. Con el final de la amenaza soviética la posibilidad de justificar este tipo de actividades se ha tornado sumamente complicada y requiere de la preparación y del contexto adecuados. Además, ante la difuminación del interés nacional, salvo en situaciones de crisis o de oportunidades importantes para sus intereses, los miembros del Congreso tienden a no mirar más allá de los problemas de sus distritos.

Todos estos factores se refuerzan con la hostilidad de la opinión pública estadounidense hacia un incremento en la ayuda exterior ${ }^{2}$ y por la obsesión de determinados congresistas en reducir el déficit presupuestario (Lancaster, 2000: 29).

En este nuevo contexto, el análisis de cómo se forjó un paquete de ayudas de 1.300 millones de dólares para la lucha contra el narcotráfico en Colombia y la región andina es una referencia imprescindible para entender las nuevas y viejas dinámicas que mueven a la clase política y a las burocracias estadounidenses en la elaboración de la política exterior hacia América Latina.

La consolidación de Colombia como principal suministrador de cocaína de los EE.UU., y de forma creciente de heroína, sumada a la continuidad de las dos últimas grandes guerrillas del hemisferio, las FARC y el ELN, a las que Washington acusa de nutrirse del dinero del narcotráfico y de generar inestabilidad y de hacer peligrar sus intereses en el país andino, han situado a este país en un lugar primordial en la elaboración de su política exterior hacia América Latina.

Colombia combina la difícil ecuación de la lucha contra la inestabilidad insurgente, narcotráfico y de la promoción de la democracia y de los intereses económicos de los EE.UU. y ejemplifica, además, la importancia de la política doméstica en relación con el problema del narcotráfico.

En el presente artículo se expone cómo la guerra contra las drogas ofrece dos ventajas que son aprovechadas por determinados emprendedores políticos para hacer valer sus soluciones a los problemas de Colombia. Por un lado, y dada la difusa línea entre contrainsurgencia y lucha contra la droga suscitada a raíz del término narco-guerrilla, la guerra contra las drogas sirve para justificar el apoyo a los militares colombianos sin

2. El 80 por ciento de los estadounidenses consideran que su país destina excesivos fondos en ayuda externa, lo cual se basa en el erróneo convencimiento de que el Congreso de los EE.UU. autoriza anualmente cifras alrededor del 15 por ciento de su presupuesto, cuando en realidad no llegan al 1 por ciento. 
generar las suspicacias que despertaría la solicitud de ayuda para misiones de contrainsurgencia. Por otro, y en especial en vísperas de procesos electorales, sirve para que la clase política estadounidense muestre que se mantiene una postura dura contra el narcotráfico en los países productores y, además, para satisfacer las demandas de determinados grupos de interés.

\section{RELACIONES ENTRE LOS ESTADOS UNIDOS Y COLOMBIA: ANTECEDENTES Y EVOLUCIÓN}

\section{II.1. El origen del narcotráfico en Colombia}

Durante la mayor parte del siglo XX, Colombia y los EE.UU. disfrutaron de cercanas y amistosas relaciones tan sólo enturbiadas por el conflicto del Canal de Panamá3. La colaboración militar y la presencia de asesores militares estadounidenses en suelo colombiano se inició durante la primera Violencia colombiana (1946-1957) cuando en el contexto del inicio de la Guerra Fría los EE.UU., alarmados por el surgimiento de guerrillas de izquierdas empezaron cooperar con el Gobierno del dictador Rojas Pinilla. El surgimiento en los años 60 de las Fuerzas Armadas Revolucionarias de Colombia (FARC), el Ejército de Liberación Nacional (ELN) y el «Movimiento 19 de abril» (M-19) en los 70, aumentaron la preocupación de Washington por incrementar sus vínculos con los gobiernos y Fuerzas Armadas colombianas. Colombia fue uno de los principales apoyos de los EE.UU. durante el programa de «Alianza para el Progreso» de J. F. Kennedy, y la estabilidad «democrática» experimentada durante el Frente Nacional (1958-1974) consolidaron a Colombia como un aliado ejemplar contra el comunismo y como un buen socio comercial.

Las cordiales relaciones empezaron a deteriorarse a mediados de los años 70 con el surgimiento del problema del narcotráfico. El negocio de la droga comenzó a florecer en el país andino como resultado de los altos precios y los elevados costes en transporte provocados por políticas antidroga en Turquía y Oriente Medio. Estos factores llevaron a los cárteles internacionales a buscar lugares más cercanos al mercado estadounidense que les permitiera reducir costes. La cocaína, más barata que el opio y la heroína y más fácil de transportar, proporcionó la solución. Colombia no sólo ofrecía la ventaja geográfica de tener acceso a las dos costas estadounidenses (Keen, 1996: 514), sino que además contaba con una importante tradición contrabandista, con la infraestructura financiera necesaria, tierras fértiles, el clima adecuado y mano de obra abundante.

La inmensa mayoría de las plantaciones de hoja de coca se fueron consolidando como resultado del desplazamiento de campesinos afectados por los diferentes conflictos

3. Los EE.UU. apoyaron la insurrección de grupos independentistas para a cambio obtener la licencia del canal. Como resultado Colombia perdió el territorio que hoy día conforma Panamá. 
armados colombianos a zonas donde la presencia del Estado era francamente débil cuando no inexistente (Thoumi, 2001).

La obtención de beneficios del negocio del narcotráfico se fraguó por la división del trabajo entre los productores y exportadores colombianos, centrados en Medellín y Cali, y los mayoristas domésticos estadounidenses, banqueros y blanqueadores de dinero, actuando todos ellos con casi total impunidad. Cabe destacar que hasta mediados de los años 90, los narcotraficantes colombianos se centraban fundamentalmente en procesar la materia prima proveniente de Perú, Bolivia y Ecuador y exportarla a los EE.UU. y a otros centros de consumo (Keen, 1996: 514).

En 1991 Colombia era ya el tercer productor de hoja de coca del mundo, y en menos de una década acabaría desplazando a Perú y Bolivia y pasando a realizar todo el proceso de la cocaína, y de forma creciente de la heroína (Thoumi, 2001).

Junto a su idoneidad para el cultivo de hoja de coca, tuvieron que darse tres situaciones para que Colombia desbancara a Bolivia y Perú y se convirtiera en el primer productor mundial y primer suministrador de los EE.UU. Por un lado, las agresivas campañas de interceptación de vuelos llevadas a cabo por Fujimori con la ayuda de Washington hicieron cada vez más complicado el transporte de la materia prima a Colombia. En segundo lugar, tanto los paramilitares como las guerrillas vieron ventajosa la promoción de cultivos ilegales para ganarse el apoyo de los campesinos en las zonas controladas por ellos. Además, el final del apoyo financiero soviético llevó a las FARC a buscar fuentes alternativas de financiación (Thoumi, 2001).

Si bien durante la Guerra Fría las acciones militares contra la guerrilla y el narcotráfico en Colombia habían discurrido de forma independiente, en el nuevo marco de relaciones estas conexiones abrirían la puerta para conseguir fondos del Congreso para los militares colombianos.

\section{II.2. La guerra contra las drogas en los EE.UU.}

La guerra contra las drogas no fue considera como una prioridad en las agendas estadounidenses hasta la presidencia de Richard Nixon, quien enfatizando su relación con el crimen organizado logró un incremento sustancial en el presupuesto antinarcóticos y fue el primer presidente en destacar la necesidad de golpear el lado de la oferta (Bertram, 1996: 105)

Desde que Nixon (1969-1974) lanzara la primera guerra contra las drogas, los presidentes estadounidenses han confiado en tres instrumentos fundamentales para hacer frente al narcotráfico: 1) el poder para persuadir a la opinión pública; 2) el poder para lanzar iniciativas legislativas; 3 ) y el poder para dirigir la burocracia federal (Bertram, 1996: 104).

Tres factores domésticos han condicionado el desarrollo las políticas antinarcóticos estadounidenses. Por un lado, se ha dado una fuerte conexión entre años electorales y 
fuertes incrementos en la ayuda antinarcóticos, debido a la consolidación de las drogas como un top issue entre la opinión pública. Este hecho ha dado pie a una importante correlación entre año electoral y la aprobación de legislación relevante referente la lucha contra la droga. La práctica totalidad de este tipo de legislación ha sido siempre promovida en años electorales (Bertram, 1996: 137).

Otra constante que se ha mantenido y que se puso de manifiesto durante las presidencias de Carter (1977-1981) y Ford (1974-1977) han sido los obstáculos existentes en la clase política estadounidense para lograr una redefinición del problema del narcotráfico y su necesidad de mantener una línea dura especialmente en vísperas de procesos electorales. Ford intentó disminuir la retórica de «guerra» de Nixon, y solicitó, sin éxito, la búsqueda de un equilibrio y complementación de las estrategias de reducción de la oferta y la demanda. Por su parte, Carter se encontró con una gran oposición de la clase política más moralista de Washington en sus intentos de legalizar el consumo de marihuana y sustituir las penas criminales por posesión por multas civiles (Bertram, 1996: 109).

Con Reagan y Bush, la expansión de la represión del lado de la oferta tanto fuera como en los EE.UU. alcanzaron nuevos techos (Bertram, 1996: 116). A Reagan le tocó vivir el boom del consumo de la cocaína en los EE.UU. y una creciente presión de sus constituyentes para acabar con posturas «permisivas» de las dos presidencias previas. Respaldado por los medios de comunicación y respondiendo a la creciente alarma social Reagan convirtió la lucha contra las drogas en una cruzada nacional durante su primer mandato (Bertram, 1996: 137).

Desde los años 80, del presupuesto anual antidroga sólo se ha utilizado un promedio de un tercio en prevención y tratamiento, destinándose el resto a promover el cumplimiento de la ley ${ }^{4}$.

\section{II.3. Militarización de la guerra contra las drogas}

Las presiones para lograr una militarización de la guerra contra las drogas en América Latina se iniciaron en 1981 durante la presidencia de Reagan, quien recibió crecientes presiones por parte del House Select Committe on Narcotics Abuse and Control. Pese a que la guerra contra las drogas no suponía una prioridad en la agenda política del Departamento de Defensa dada la imposibilidad de ganarla en términos reales en 1986 funcionarios estadounidenses coordinaron con éxito una acción militar conjunta con las Fuerzas Armadas bolivianas (Operation Blast Furnace) contra instalaciones para el procesamiento de cocaína en Bolivia (Bagley y Walker, 1994: 2-3). Esta acción sería la precursora de la denominada «Iniciativa Andina» lanzada en 1989 por

4. ABCNEWS.com Addicted to Failure? By John Cochran, 22 de septiembre de 1999. 
George Bush para frenar el tráfico de drogas en los lugares de producción de Bolivia, Perú y Colombia. El programa de Bush suponía un esfuerzo sin precedentes en la lucha contra las drogas en los países productores, e incorporaba ayuda militar, económica y asesoramiento en el cumplimiento de la ley. La invasión de Panamá en ese mismo año fue la primera operación a gran escala justificada en términos de la lucha contra el narcotráfico. Sirvió también para lanzar un claro mensaje a los países andinos en el que se dejaba entrever que aquellos que cooperaran en la guerra contra la droga obtendrían beneficios económicos y ayuda militar, pero en caso contrario, serían objeto de sanciones económicas y quizá de una intervención militar (Steiner, 1999: 163).

Si bien la lucha contra el narcotráfico era ya importante para Washington, durante la Administración de George Bush cobraría un nuevo sentido. En la transición hacia un nuevo orden mundial, a falta de enemigos externos, el narcotráfico ganó enteros y se empezó a situar como una de las mayores amenazas para los EE.UU. y como un asunto prioritario en el diseño de la política exterior.

A medida que la lucha contra las drogas centrada en la represión de la oferta fue conformándose como una cuestión primordial para la clase política estadounidense, tuvo lugar una narcotización de la política de Washington hacia Colombia. Mientras los EE.UU. se consolidaban como el principal consumidor de estupefacientes, Colombia le iba a la par como suministrador y a mediados de los 90, también como productor.

Colombia pasó a adoptar políticas a corto plazo como respuesta reacción a las imposiciones o presiones de Washington. En 1980, bajo la presidencia de Turbay (1978-1982), se firmó el primer tratado de extradición con los EE.UU. en un clima de cordialidad (Steiner, 160-1961: 1990).

Cabe destacar que hasta la presidencia de Betancur (1982-1986), Colombia no fue marginada durante la Guerra Fría por el tema de las drogas ni éste condicionó la agenda bilateral entre ambos países. Washington empezó a usar amenazas comerciales a raíz de que Betancur se negara a aplicar el acuerdo de extradición firmado por Turbay por considerarlo inconstitucional. Betancur daría marcha atrás tras el asesinato del ministro de Justicia Rodrigo Lara, entregando los primeros cuatro narcotraficantes a los EE.UU. (Steiner, 161: 1990) e iniciando una guerra contra los «señores de la droga», que duraría 10 años y que consolidaría al narcotráfico como un tema central de las relaciones con los EE.UU.

Ante el fuerte aumento del consumo doméstico en los EE.UU., Washington incrementó la presión sobre el Gobierno de Virgilio Barco (1986-1990). A mismo tiempo, el asesinato por parte de los narcotraficantes de numerosos jueces, periodistas y políticos opuestos a sus actividades acabó por alarmar a las elites colombianas, que al ver que el poder de los narcotraficantes se les estaba escapando de las manos decidieron incrementar su cooperación con los EE.UU. (Keen, 1996: 515).

De cara a lograr un mayor esfuerzo por parte de los países productores, los EE.UU. establecieron en 1986 el sistema de certificación. Por este sistema, a principios de año Washington certifica qué países están cooperando para cumplir los objetivos de la Convención de la ONU sobre drogas de 1988. En caso negativo, un país puede llegar a 
perder la ayuda externa estadounidense (salvo la destinada a la lucha contra la droga) o dada la influencia de los EE.UU., a perder créditos de organismos multilaterales.

La cooperación entre Colombia y los EE.UU. dio como fruto la desarticulación a mediados de los 90 de los carteles de la cocaína de Cali y de Medellín. Pese a ello, no mejoró el problema del narcotráfico, ya que los dos grandes carteles fueron reemplazados por numerosos y más pequeños narcotraficantes independientes («cartelitos»), mucho más difíciles de identificar y de controlar (Sefarino, 1999: 2).

\section{II.4. Clinton y la lucha contra las drogas}

Con la llegada a la Presidencia de Clinton, además de llevar a cabo la cooperación antinarcóticos, especialmente centrada en el apoyo a la policía colombiana, Washington dio su apoyo al proceso de paz colombiano.

Al contrario que Reagan, Nixon y Bush, el problema de la droga no fue sin embargo un asunto prioritario en la agenda de Clinton hasta el final de su segundo mandato. Hasta entonces su política contra las drogas fue más bien una reacción a las presiones ejercidas por la opinión pública y los republicanos en el Congreso.

Durante la campaña electoral que le aupó a la Presidencia en 1992, Clinton intentó dar un cambio en la retórica y redefinir el problema de la droga reconociendo el fracaso de las estrategias centradas en perseguir la oferta, así como la conveniencia de aumentar los gastos en tratamiento y prevención en los EE.UU. (Youngers, 1997).

No obstante, una vez en la Presidencia, la retórica no concordó con las acciones y Clinton mantuvo básicamente los ratios de gasto en los esfuerzos de reducción de la oferta y de la demanda (Youngers, 1997). Clinton, como ya sucediera con Ford y Carter, no logró cambiar la dinámica de la guerra contra las drogas y fracasó en sus intentos de que el Congreso aprobara más fondos para los consumidores habituales de cocaína. Ante las crecientes presiones republicanas, no tuvo interés en correr riesgo político alguno en un tema que hubiese requerido una lucha incierta y prolongada en el Congreso. Sus esfuerzos para alterar la concepción del problema de la droga fueron en todo momento modestos y cautos (Bertram, 1996: 117).

Si durante el primer mandato de Clinton la guerra contra las drogas fue secundaria, en 1995, pocos meses antes de que éste finalizara, se inició un importante viraje que culminaría en el paquete de ayudas de 1.300 millones al Plan Colombia y a la región andina.

En noviembre de 1995 importantes encuestas indicaban un aumento alarmante en el consumo de drogas por parte de los adolescentes estadounidenses. En vísperas de un nuevo proceso electoral a la Presidencia, los republicanos, que se habían hecho con el control del Congreso en enero de ese mismo año, comenzaron a enfatizar la debilidad de Clinton como líder a la hora de hacer frente al problema de la droga, y le señalaron como principal culpable del aumento. Ante esta situación, y para mostrar su 
fortaleza como dirigente, Clinton dio un giro y pasó a promover una serie de duras iniciativas contra el narcotráfico. A escala doméstica, introdujo una iniciativa para que se impusiera una prueba de detección de consumo de drogas a todos aquellos individuos arrestados por delito federal (Youngers, 1997).

Estos hechos coincidieron con el «escándalo Samper», de manera que las buenas relaciones entre ambos países desde la llegada de Clinton a la Casa Blanca sufrieron una profunda crisis. Ernesto Samper (1994-1998), fue acusado de haber aceptado alrededor de 6 millones de dólares del cartel de Cali para financiar su campaña electoral de 1994 (Shifter, 2000: 52). Ante la proximidad de las elecciones, Clinton no dudó en mostrarse duro y como resultado, el visado de Samper para viajar a los EE.UU. fue cancelado. A escala internacional, Clinton demostró a la opinión pública estadounidense su firmeza ante las drogas reduciendo las ayudas financieras a Colombia por su falta de colaboración en la lucha contra el narcotráfico y anticipándose así a las intenciones del senador republicano Jesé Helms de introducir legislación para dicho propósito (Youngers, 1997).

En 1996, en el contexto del deterioro de las relaciones con el Gobierno de Samper, las ayudas al Ejército colombiano fueron suspendidas por su probada participación en violaciones de los derechos humanos y toda la ayuda militar pasó a estar dirigida únicamente a la Policía Nacional colombiana.

También en 1996, el Congreso de los EE.UU. adoptó la denominada «Enmienda Leahy» introducida por el senador demócrata Patrick Leahy, que prohíbe todo tipo de ayuda administrada por el Departamento de Estado a aquellas unidades militares colombianas cuyo personal haya estado involucrado en serias violaciones de los derechos humanos.

Pese a esta situación, el Congreso siguió apoyando ayuda destinada a la lucha antinarcóticos, aunque con la condición de que no fuera utilizada en la lucha contra grupos insurgentes y de que se respetaran los derechos humanos por parte de las fuerzas de seguridad colombianas. Estos dos factores motivaron que la ayuda exterior estuviera principalmente centrada en la policía colombiana y no en sus fuerzas armadas.

\section{II.5. Clinton y la narcoguerrilla}

El aumento de la relevancia del problema de la droga y la necesidad de Clinton de mostrar más dureza al respecto coincidieron con intereses económicos y geopolíticos. Pese a la ausencia de la amenaza soviética, las FARC y el ELN siguieron constituyendo una amenaza para los EE.UU. por su oposición al neoliberalismo, por generar inestabilidad y por amenazar sus intereses en el país andino. Sin embargo, y como se ha mencionado anteriormente, con el final de la Guerra Fría la injerencia en los asuntos colombianos se hizo mucho más difícil de justificar ante el Congreso y ante la opinión pública. El concepto de narcoguerrilla ofreció la solución. 
De especial relevancia para conjugar intereses domésticos e internacionales fue el nombramiento del general retirado y héroe de la Guerra del Golfo, Barry McCaffrey, como nuevo zar antidrogas. McCaffrey había sido jefe del Comando Sur estadounidense en Panamá, donde llevó a cabo la coordinación militar en la lucha antinarcóticos, y tenía excelentes relaciones con los militares andinos (Youngers, 1997).

A raíz del nombramiento de McCaffrey, la asistencia estadounidense a Colombia y al resto de los países andinos comenzó a incrementarse de forma significativa (Youngers, 1997). Como posteriormente se explicará, McCaffrey resultaría un emprendedor clave en la inclusión del tema en la agenda política y en la elaboración del paquete de ayudas de 1.300 millones de dólares. McCaffrey se convirtió además en el principal valedor del concepto de narcoguerrilla.

Si bien el término narcoguerrilla fue acuñado por primera vez en la etapa de Ronald Reagan por el embajador en Colombia para justificar el desvío de fondos contra el narcotráfico para ser empleados contra la guerrilla (Steiner, 171-172), hasta el nombramiento de McCaffrey la guerra contra las drogas y la lucha contra la guerrilla discurrieron por lo general por caminos separados.

La llegada de Andrés Pastrana a la Presidencia colombiana en 1998 supuso una notable mejora en las relaciones bilaterales entre ambos países, que se tradujo en un incremento sustancial de la ayuda exterior al país andino y en la certificación de Colombia. En octubre de 1998, el Congreso volvió a apoyar la ayuda a los militares colombianos para que asistieran a la policía en la lucha antinarcóticos. En 1999, la ayuda militar estadounidense se incrementó notablemente, alcanzando alrededor de 300 millones de dólares, cifra que convirtió a Colombia en el tercer receptor de ayuda estadounidense, superado tan solo por Egipto e Israel5. En ese mismo año, tuvo también lugar un acuerdo entre los servicios de inteligencia de ambos países para compartir información (Shifter, 2000:52).

En otoño de 1999, y en estrecha cooperación con Washington, Pastrana lanzó el Plan Colombia para solucionar los enormes problemas de su país ${ }^{6}$. El apoyo estadounidense a este plan no se hizo esperar, y el 12 de enero del 2000, Clinton anunció que propondría al Congreso un paquete de ayuda antinarcóticos de dos años, dotado con 1.300 millones de dólares, con objeto de apoyar al Plan Colombia en la guerra contra la droga colombiana, así como a la región andina. Del total, 1.025 millones irían destinados a Colombia con el objetivo fundamental de reducir la producción de hoja de coca en las zonas controladas por las FARC. Si a esta cifra se le añadían los 300 millones ya presupuestados para los años fiscales 2000 y 2001, la cifra ascendía a 1.300 millones de dólares. La propuesta de Clinton suponía un compromiso presupuestario sin precedentes

5. A New War. The Economist, 15 de enero de 2000.

6. Drugs, war and Democracy, The Economist, 19 de abril de 2001. General AcCounting OfficE. Drug Control: Narcotics Threat From Colombia Continues to Grow. GAO/NSIAD-99-136, junio 1999. 
comparado con los 66 millones de dólares presupuestados en 1996, e incluso con los 317 millones de 1999 (ver Gráfico I).

Igualmente sorprendente fue el hecho de que el 67 por ciento de la ayuda estuviera destinada a las Fuerzas Armadas colombianas. El Congreso, que hasta entonces se había mostrado desconfiado a la hora de aprobar grandes sumas de ayuda para los militares, e inquieto ante una creciente involucración de los EE.UU. en el conflicto colombiano, cambió de opinión y aunque con ciertas restricciones, aprobó el paquete en junio del 2000 de forma bipartidista, siendo firmado como ley en julio.

¿Cómo y por qué el Ejecutivo estadounidense incluyó en su agenda el que es mayor paquete de ayudas a un país de América Latina desde el final de la Guerra Fría? ¿Cuál fue el proceso que siguió el paquete a su paso por el Congreso? ¿Qué consecuencias tiene en el diseño de la política exterior estadounidense hacia América Latina en la pos-Guerra Fría?

GRÁFICO I

EvOLUCIÓN DE LA AYUDA EXTERIOR DE LOS ESTADOS UNIDOS A COLOMBIA EN MILLONES DE DÓLARES POR AÑO FISCAL

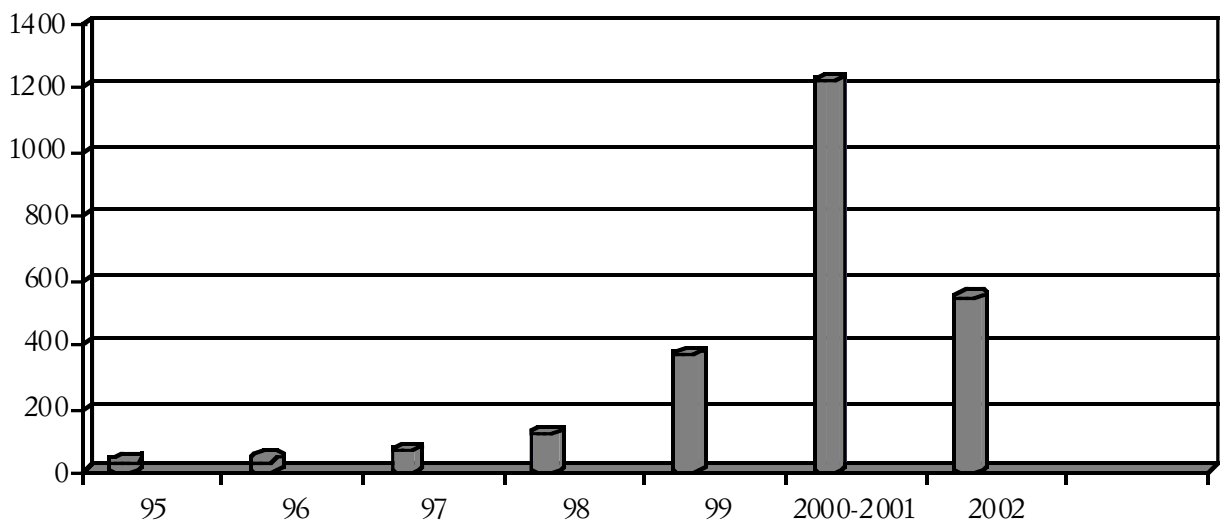

Fuente: Nina M., SeFarino, Colombia: Summary and Tables on U.S. Assistance, FY1989-FY2003. Washington: Congressional Research Service, 3 de mayo de 2002. 


\section{CÓMO Y POR QUÉ CAYÓ EL ASUNTO EN LA AGENDA DEL EJECUTIVO ESTADOUNIDENSE}

A la hora de prever y entender el proceso de elaboración de la política exterior en Washington, resulta fundamental conocer cómo se conforman las agendas políticas. A este respecto, la teoría de las Múltiples Corrientes de John W. Kingdon resulta sumamente útil para determinar cómo un asunto cae en la agenda del Ejecutivo, por qué unos asuntos son considerados importantes y otros son negados y por qué los encargados de la elaboración de políticas prestan atención a unos problemas y a otros no.

Para responder a estas preguntas, Kingdon identifica tres corrientes diferentes y relativamente independientes: la de los problemas, la de las comunidades de expertos y la de la política. Estas tres corrientes se mueven a través del sistema político estadounidense, y en momentos críticos coinciden, incrementándose de forma sustancial las posibilidades de que un determinado asunto caiga en la agenda política (Sabatier, 1999: 76). Entre ellas se mueven e interaccionan una serie de participantes que acaban por incluir los asuntos en las agendas políticas. Kingdon distingue entre participantes dentro del Gobierno (el presidente de los EE.UU., el personal de la Oficina del Ejecutivo, y los puestos políticos en otros departamentos y oficinas, funcionarios de carrera, congresistas en Capitol Hill y sus equipos de asesores), y participantes externos al Gobierno (grupos de presión, académicos, consultores, medios de comunicación, partidos políticos, candidatos electorales y la opinión pública).

La primera corriente identificada por Kingdon contiene problemas. Para que los problemas sean reconocidos como tales, primero tienen que ser detectadas una serie de situaciones o condiciones. Estas situaciones pueden ser identificadas mediante tres mecanismos: 1) a través de indicadores, más o menos sistemáticos, tanto de agencias gubernamentales como no gubernamentales, que indican su existencia (p. ej. la mortalidad infantil);2) debido a acontecimientos dramáticos o crisis (p. ej. un avión se estrella y llama la atención sobre la seguridad aérea);3) mediante la información de programas que no están dando los resultados esperados ( $\mathrm{p}$. ej. los electores mandan cartas a sus congresistas protestando por el mal funcionamiento de una autopista). En el momento que los encargados de elaborar la política sienten que algo debe hacerse para solucionar esas situaciones o condiciones, éstas se convierten en problemas (Kingdon, 1995: 90-115).

La corriente de «las comunidades de expertos» contiene ideas generadas por investigadores en Think tanks, por burócratas, académicos, asesores de congresistas, analistas de los grupos de interés, que están preocupados por un determinado asunto y que presentan ideas sobre cómo deben afrontarse dichas cuestiones. Dentro de las comunidades políticas juegan un papel determinante lo que Kingdon llama emprendedores de la política. Una vez que una condición o situación ha sido reconocida como un problema, los emprendedores son los que le adjuntan una solución para llamar así la atención de los que realmente tienen la capacidad para incluirla en la agenda. Los emprendedores se mueven astutamente para crear el clima favorable para que la política sea propuesta y no les importa gastar tiempo, energía, reputación, y algunas veces dinero, si pueden lograr hacer valer sus soluciones a los problemas. Si la solución que 
se adjunta al problema se presenta de forma detallada y resulta viable a la hora de ser llevada a la práctica, tendrá más posibilidades de ser aceptada. El éxito personal, el hecho de poder incluir sus valores en una determinada política o el disfrutar siendo parte de la acción es lo que según Kingdon les lleva a defender una solución determinada (Kingdon, 1999: 122-23).

Por último, Kingdon distingue «la corriente de la política», compuesta por los cambios en la opinión pública, las campañas de los grupos de presión, los resultados electorales, las distribuciones partidistas o ideológicas en el Congreso y el cambio de Administración o de miembros en el Congreso. El papel de la opinión pública tiene un peso significativo en la conformación de las agendas cuando los encargados de elaborar las políticas perciben, por ejemplo a través de encuestas de opinión, que se ha producido un cambio en la opinión de un número significativo de ciudadanos en relación con un determinado asunto. De igual forma, la percepción de que la mayoría de los grupos de presión apuntan en una dirección les sirve para medir el nivel de consenso o disidencia en la arena política. Por último, un cambio en la composición del Congreso o la llegada de un nuevo presidente puede conllevar importantes cambios en las agendas políticas. Tal como señala Kingdon, la combinación de los cambios en la opinión pública y un cambio de Administración son los elementos de más peso para que se produzcan cambios en las políticas (Sabatier, 1999: 76-77).

Como se ha mencionado anteriormente, cuando las tres corrientes se juntan en momentos críticos, las posibilidades de un cambio en una determinada política suben notablemente, y se abre la puerta para el cambio político. Dichas oportunidades aparecen, bien por la existencia de un problema relevante, o bien porque se produce algún tipo de cambio en la corriente de la política. Es entonces cuando los emprendedores políticos deben ser capaces de identificar la ocasión, llamar la atención sobre las soluciones que ellos adjuntan a los problemas y presionar para que sean aceptadas por los políticos. En el momento en que las personas encargadas de tomar las decisiones se sienten presionados por un problema, acuden en búsqueda de soluciones y, si las encuentran, incluyen el asunto en su agenda (Sabatier, 1999: 77-78).

El paquete de ayudas a Colombia fue incluido en la agenda del presidente de los EE.UU. Bill Clinton como resultado de la conjunción de estas tres vertientes, tal como se expone a continuación.

\section{III.1. La corriente de los problemas: el nuevo boom de la droga, el conflicto armado y la crisis económica, política y social de Colombia.}

La primera clave para entender cómo se generó el paquete de ayudas, es el compuesto por tres importantes problemas que sufre Colombia, que repercuten de forma significativa en el interés nacional estadounidense y que necesitan ser solucionados o al menos abordados por todo Ejecutivo estadounidense: 1) el narcotráfico; 2) el conflicto 
armado colombiano; 3) la crisis económica, política y social colombiana. Los cambios experimentados en esta corriente en 1999, año en que se produjo un recrudecimiento de estos problemas, abrirían la ventana para la búsqueda de nuevas soluciones.

\section{III.1.1. El nuevo boom de la droga}

Colombia se ha consolidado como uno de los principales centros internacionales del narcotráfico. Se calcula que en la actualidad los ingresos provenientes del tráfico de estupefacientes suponen entre el 25 y el 35 por ciento del valor total de las exportaciones colombianas (Shifter, 1999: 16), y que le reportan al país unos 4.000 millones de dólares al año (alrededor del 5 por ciento del total del PNB que asciende a 80.000 millones de dólares) (Sefarino, 1999: 2). Si bien es cierto que el tráfico de drogas llevaba veinte años operando en Colombia, en el verano de 1999 se detectó un enorme incremento en los niveles de producción de hoja de coca. En junio de 1999, la Oficina General de Control (General Accounting Office) de la Casa Blanca informaba al Congreso de un nuevo boom de la droga en Colombia. El informe señalaba que pese a las agresivas campañas de erradicación de cultivos de hoja de coca, éstos habían aumentado casi un 50 por ciento desde 1996 (de 67.200 hectáreas cultivadas en 1996 se había pasado a 101.800 hectáreas en 1998). Además, la producción de amapola, hasta el momento prácticamente inexistente, había también aumentado. En sólo tres años, Colombia había sobrepasado a Bolivia y Perú para convertirse en el primer productor mundial de hoja de coca, suministrando el 90 por ciento del total de mercado estadounidense, y la mayor parte de la heroína de la Costa Este de los EE.UU. El aumento se había producido especialmente en las regiones de Caquetá y Putumayo, al sur de Colombia, espacios no controladas por el Gobierno colombiano y donde operan las FARC y los grupos paramilitares. El informe concluía que al ritmo que iba Colombia, en dos años sería capaz de aumentar la producción de hoja de coca en otro 50 por ciento ${ }^{7}$.

Sin duda se trataba de una noticia alarmante para Washington. Las drogas ilegales cuestan anualmente a los EE.UU. 52.000 vidas y unos gastos para la sociedad estadounidense de ciento diez mil millones de dólares al año (Salazar, 2001: 2). A ello hay que sumar la criminalidad entre bandas que luchan por hacerse con las redes de distribución en las grandes ciudades estadounidenses y la correlación entre consumo de estupefacientes y violencia.

Pese a los éxitos en la reducción de la producción en Perú y Bolivia (ver Gráfico II) mediante la combinación de políticas de erradicación e interceptación, la estrategia estadounidense no había funcionado en Colombia. Además, no existían evidencias de una reducción significativa a escala regional y los datos parecían más bien indicar un

7. General Accounting Office. Drug Control: Narcotics Threat From Colombia Continues to Grow. GAO/NIAD, junio 99-136. 
movimiento de la producción de Bolivia y Perú a Colombia. Este dato repercutía de forma significativa en los intentos para reducir la llegada de droga a los EE.UU., y en los esfuerzos por reducir el consumo.

\section{GRÁFICO II}

EVOLUCIÓN DEL NÚMERO DE HECTÁREAS DE CULTIVOS DE HOJA DE COCA EN LOS PAÍSES ANDINOS

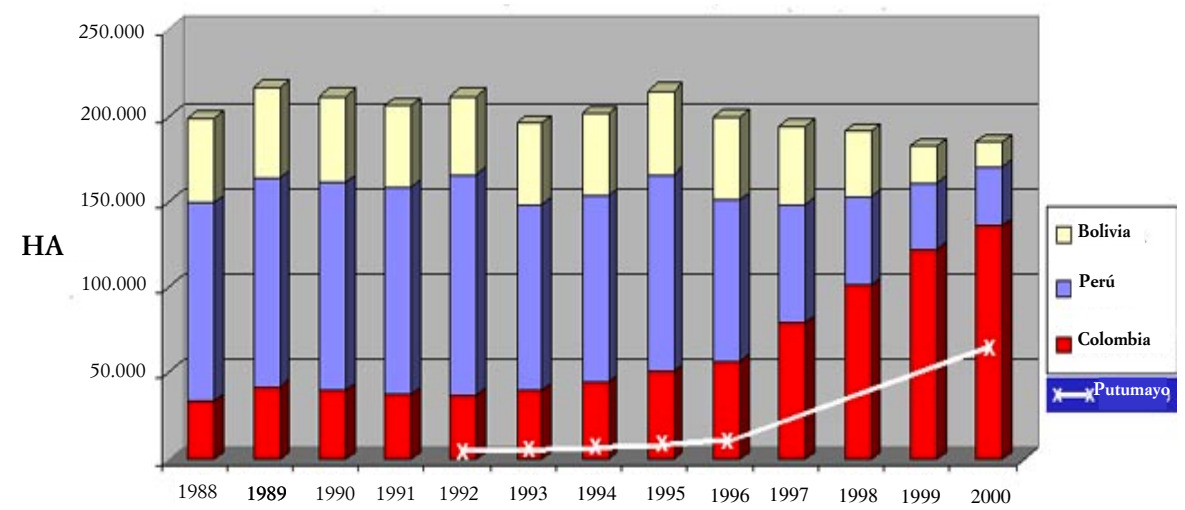

Fuente: Intervención de Adam Isacson. Centro para las Políticas Internacionales, Escuela Superior de Administración Pública. Bogotá, Colombia 16 de junio de 2001.

Los EE.UU. siguen siendo el principal consumidor de cocaína del mundo, aunque en la actualidad el consumo se encuentra estancado (Tuhomi, 2001). Si bien es cierto que el número de consumidores ocasionales de cocaína se ha reducido a la mitad en los últimos 10 años, el número de consumidores habituales durante el mismo período de tiempo se ha mantenido estable (ver Gráfico III). Según la Oficina Nacional de la Política Antidroga (Office of National Drug Control Policy), en 1999 más de 3 millones de estadounidenses eran consumidores habituales de cocaína. En el caso de la heroína, los datos eran aún más desalentadores. El número de consumidores ocasionales de heroína en 1999 era de 484.000, casi el triple de las cifras de 1988. En cuanto al número de consumidores habituales de heroína, si bien se redujo en el período 1990-1992, probablemente debido al impacto del SIDA, en los años siguientes volvió a repuntar, situándose en 1999 en cifras cercanas al millón (ver Gráfico IV)8.

Los esfuerzos por combatir la oferta, encaminados a reducir las exportaciones y limitar la demanda de droga por el encarecimiento de los precios han sido también 1988-1998.

8. Office of National Drug Control Policy. What America's Users Spend on Illegal Drugs 
desalentadores. En los últimos diez años, el precio de la cocaína en los puntos de entrada de los EE.UU. se ha mantenido constante (ver Gráfico v) y el de la heroína ha bajado con respecto al período 1988-19929.

GRÁFICO III

ESTIMACIONES SOBRE EL NÚMERO DE CONSUMIDORES DE COCAÍNA 1988-2000

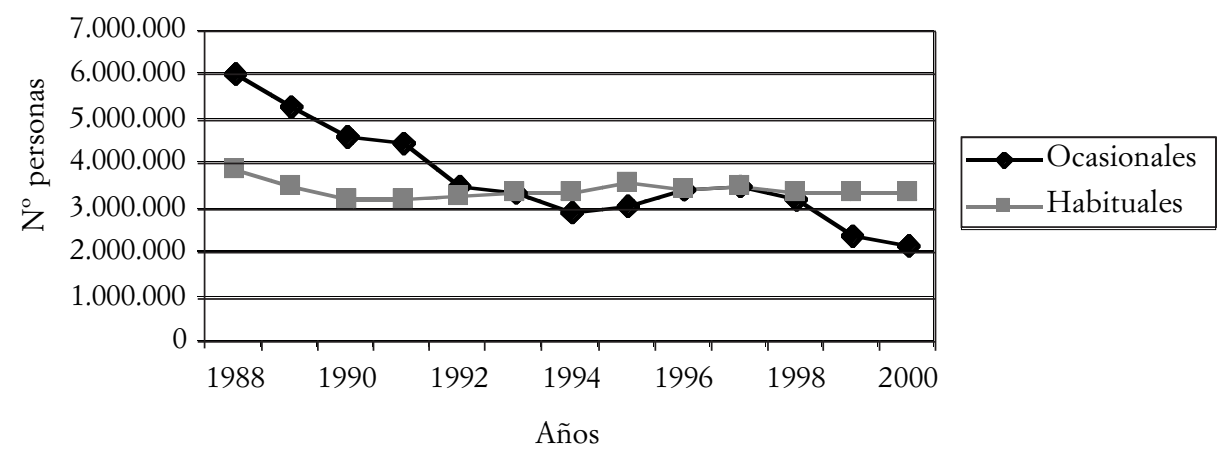

Fuente: Office of National Drug Control Policy. What America's Users Spend on Illegal Drugs 1988-1998.

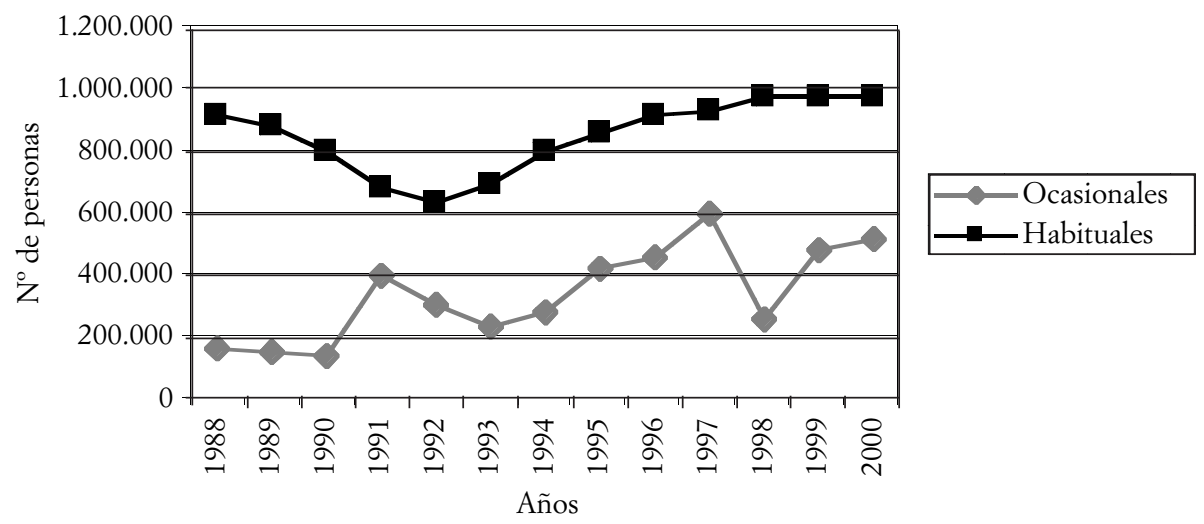

Fuente: Office of National Drug Control Policy. What America's Users Spend on Illegal Drugs 1988-1998.

9. A crop that refuses to Die. The Economist, 4 de marzo de 2000. 


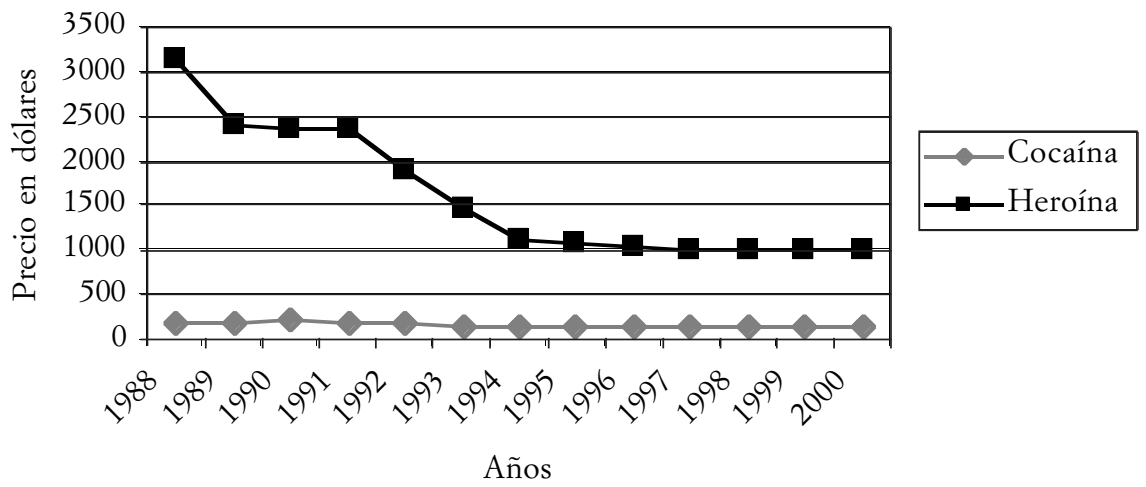

Fuente: Office of National Drug Control Policy. What America's Users Spend on Illegal Drugs 1988-1998.

III.1.2. El conflicto armado colombiano: la narcoguerrilla y los paramilitares

Si con el final de la Guerra Fría se esperaba que a los procesos de paz en Centroamérica les siguiera el de Colombia, nada más lejos de la realidad. Tras más de 40 años de conflicto armado, las guerrillas colombianas mantienen una posición fuerte, están mejor financiadas que nunca y los esfuerzos por lograr un acuerdo de paz no han obtenido ningún resultado esperanzador.

Se calcula que el número de guerrilleros de las FARC oscila entre 10.000 y 15.000 , mientras que el del ELN se cifra entre 3.000 y 6.000. Entre los dos grupos controlan o tienen influencia sobre los gobiernos locales de alrededor del 40 ó 50 por ciento del territorio colombiano (Sefarino, 2001: 9).

Se calcula que las FARC han tenido relación con el tráfico de drogas desde el primer boom de la cocaína a finales de los 70 y principios de los 80 . El grado de participación de las FARC y del ELN en el tráfico de droga varía ampliamente según las fuentes. Funcionarios del Gobierno estadounidense estiman que alrededor de dos tercios de las FARC y un tercio del ELN presentan algún tipo de vínculo con el tráfico de drogas. La participación se basa en los impuestos que cobran a los narcotraficantes por la protección de cultivos, laboratorios, instalaciones para el almacenamiento y campos de aviación (Sefarino, 2001: 11-12).

Autoridades estadounidenses del Departamento de Defensa destacan la profunda participación de las guerrillas en el negocio del narcotráfico y cifran los beneficios de 
los grupos armados procedentes de estas actividades entre 500 millones y 600 millones de dólares ${ }^{10}$.

De acuerdo con una filtración de los servicios de inteligencia estadounidenses al periódico The New York Times, de los beneficios anuales de los dos grupos (unos 900 millones de dólares), entre 30 y 100 millones de dólares proceden de los impuestos que las guerrillas cobran a los narcotraficantes, y el resto derivan de la extorsión y de los secuestros ${ }^{11}$.

¿Cómo perjudican las guerrillas el interés nacional estadounidense? Junto a la oposición de las FARC y el ELN al libre comercio propugnado por Washington, los grupos guerrilleros atacan y extorsionan a compañías estadounidenses que operan en Colombia, generan inestabilidad regional y han llevado a cabo secuestros y asesinatos de ciudadanos estadounidenses ${ }^{12}$. Además, bajo su protección se ha disparado la producción de hoja de coca y de amapola, lo que hace más acuciante la necesidad de poner fin a sus actividades, ya sea por la vía armada o por la vía de la negociación. Tras el anuncio del nuevo boom de la droga en las zonas controladas por las FARC, el concepto de «narcoguerrilla» cobró mucha más relevancia de la que se le había dado hasta la fecha, y dio pie a que el problema del conflicto armado colombiano se abordara desde una óptica diferente. La vinculación entre guerrilla y narcotráfico conectaba a los grupos insurgentes con el problema doméstico estadounidense de consumo de estupefacientes. Además, ahora se trataba de un tema con mucho más calado entre la opinión pública y la clase política estadounidense, que comenzaría a preguntarse si el fracaso en Colombia de las exitosas estrategias en Perú y Bolivia estaba vinculado a participación de la guerrilla en el negocio del narcotráfico.

Hay que destacar que junto a la guerrilla, los grupos paramilitares se nutren también del narcotráfico. Los paramilitares surgieron en Colombia debido al fracaso del Estado en la contención de la insurgencia guerrillera, tanto por la vía armada como por la vía de la negociación. Fueron creados durante los años 80 por ricos terratenientes, con el propósito de defender sus intereses de los ataques de las FARC y del ELN, y para ayudar a los militares en al lucha contra las guerrillas. En 1997, la mayoría de los grupos paramilitares se unificaron bajo el liderazgo de Carlos Castaño y pasaron a llamarse Autodefensas Unidas de Colombia. Los paramilitares no sólo actúan como complemento del Ejército, sino que le han suplantado en muchas zonas, en especial en aquellas donde la presencia estatal ha sido tradicionalmente débil.

La permisividad militar ha colocado a los paramilitares en una situación en la que ejercen la violencia fuera de control. Sólo recientemente los paramilitares están enfrentándose directamente a la guerrilla, dado que tradicionalmente sus objetivos venían

10. General Accounting Office. Drug Control: Narcotics Threat From Colombia Continues to Grow. GAO/NSIAD-99-136, junio 1999.

11. Tim Golden y Steven Lee Myers. U.S. Plans Big Aid Package to Rally a Reeling Colombia. The New York Times, 15 de septiembre de 1999.

12. Testimonio del general Barry R. McCaffrey ante el Comité de Reforma Gubernamental de la Cámara de Representantes. 15 de febrero de 2000. 
siendo las masacres de la población civil que le da apoyo. Los paramilitares se han consolidado como un tercer grupo en la guerra civil colombiana y exigen su participación en el proceso de paz (Chernick, 1998: 32). Se estima que las tropas paramilitares cuentan con entre 5.000 y 7.000 hombres, que fueron responsables de tres cuartas partes de los asesinatos políticos colombianos de $1998{ }^{13}$.

Algunos grupos paramilitares también han sido acusados de participar en el tráfico de drogas. Aunque no existen datos oficiales sobre su grado de participación, en abril de 1998, una agencia del Gobierno colombiano catalogó a Castaño como el jefe del narcotráfico en el área de Medellín. En 1997 y 1998, en una comparecencia ante el Congreso, la U.s. Drug Enforcement Administration (DEA) acusó a Castaño de traficar con cocaína. En una entrevista, el propio Castaño reconoció que su grupo obtiene el 70 por ciento de sus ingresos de los narcotraficantes, aunque negó la participación directa de los paramilitares en el narcotráfico (Sefarino, 2000).

En 1999 el conflicto colombiano resultó especialmente dramático. Los enfrentamientos entre las FARC y grupos paramilitares alcanzaron un punto álgido en el número de atrocidades, en su amplia mayoría cometidas por estos últimos. La Oficina Gubernamental de los Derechos Humanos informó sobre 402 masacres, en las que murieron 1.836 personas (Shifter, 2000: 53).

A mediados de 1999, el proceso de paz colombiano no estaba dando los resultados esperados. En marzo, las FARC asesinaron a tres defensores de los derechos humanos estadounidenses. En julio, este grupo guerrillero lanzó una gran ofensiva. En ese mismo mes, un avión espía estadounidense RC-7B DeHavilland se estrelló en el departamento de Putumayo, falleciendo cinco americanos y dos oficiales colombianos. Estos acontecimientos incrementaron de forma importante la preocupación de muchos congresistas y acabaron por distanciar a los EE.UU. del proceso de paz colombiano, volviendo a la Administración Clinton más receptiva a las soluciones militaristas (Shifter, 2000: 52).

\section{III.1.3. La crisis económica, política y social colombiana}

El conflicto armado colombiano y el problema del narcotráfico tienen importantes repercusiones en las relaciones comerciales de Colombia con los EE.UU. En 1999 Colombia experimentó la peor crisis económica desde los años 30 y la primera recesión en 25 años ${ }^{14}$. Su Producto Nacional Bruto (PNB) se contrajo por primera vez en 50 años y la deuda externa del país pasó del 34 por ciento del PNB de 1998 al 41,3 por ciento en 1999 (unos 36.000 millones de dólares). El desempleo creció del 9 por ciento en 1995, hasta el 20 por ciento en 1999. El conflicto armado agrava aún más la crisis, dado que cuesta a Colombia alrededor del 3 por ciento de su crecimiento (Sefarino, 1999: 3).

13. Dealing with Colombia's Death-squads. The Economist, 8 de abril de 2000.

14. Testimonio del general Barry R. McCaffrey ante el Comité de Reforma Gubernamental de la Cámara de Representantes, 15 de febrero de 2000. 
La profunda crisis económica perjudica los intercambios comerciales y las inversiones de los EE.UU. en el país andino. Los EE.UU. son el primer inversor extranjero en Colombia, aportando el 40 por ciento de la inversión directa del país. Colombia es el quinto socio comercial de los EE.UU. en la región. Las exportaciones estadounidenses a Colombia alcanzaron en 1998 casi 5.000 millones de dólares, mientras que las importaciones de los EE.UU. representaron un 30 por ciento del total colombiano (Sefarino, 1999: 4).

Entre todos los intereses estadounidenses en Colombia, cabe destacar los perjuicios que las guerrillas causan a la industria del petróleo. El petróleo colombiano ha aumentado progresivamente en importancia para Washington, debido al creciente consumo nacional y a la necesidad de diversificación, dada la inestabilidad en Oriente Próximo. Colombia es el octavo suministrador de petróleo de los EE.UU., con un embarque diario de más de 330.000 barriles. La mayor inversión en el negocio del petróleo en Colombia corresponde a la asociación entre British Petroleum y la estadounidense Amoco, seguidos de Occidental Petroleum. La compañía estadounidense Occidental Petroleum, que opera desde los años 80 en el campo petrolífero de Caño Limón", en el departamento de Arauca, ha descubierto en la última década importantes reservas petroleras. En los últimos años, las FARC y el ELN atacaron en 700 ocasiones los oleoductos estatales que conducen el petróleo de Occidental hasta el puerto de exportación de Covenas, en el Caribe. El recrudecimiento del conflicto armado ha deteriorado la situación y, sólo en 1999, los grupos guerrilleros atacaron 79 veces estas infraestructuras, frente a los 55 ataques de 1996. Según el vicepresidente de la compañía, desde 1995 los ataques han provocado alrededor de 100 millones de dólares en pérdidas y la pérdida de 1,7 millones de barriles ${ }^{15}$. Estos ataques también entorpecen la exploración de nuevos yacimientos.

En un país donde la mitad de la población vive por debajo del umbral de pobreza (el 21 por ciento en la extrema pobreza), y que cuenta con un millón de desplazados por el conflicto armado y las fumigaciones de cultivos, el deterioro de la profunda depresión económica erosiona de forma sustancial los recursos del Gobierno colombiano para hacer frente a los problemas del país.

El narcotráfico, la crisis económica y el conflicto armado han erosionado enormemente la capacidad de actuación del Estado colombiano, que se encuentra ausente de gran parte del territorio y se ve impotente ante los crecientes índices de criminalidad y la corrupción. Los narcotraficantes están involucrados en la corrupción a gran escala del país, afectando negativamente la confianza de la población en sus instituciones. La ineficacia del Estado de derecho ha provocado que los ciudadanos recurran a la violencia como forma de resolución de sus disputas, y ha generado una enorme desconfianza

* Tim Golden y... U.S. Plans Big... The New York Times, 15 de septiembre de 1999.

15. Testimonio de Lawrence P. Meriage, vicepresidente ejecutivo de Servicios y Asuntos Públicos de Occidental y Gas Corporation ante el Subcomité de Justicia Criminal, Política Antinarcóticos y Recursos Humanos, 15 de febrero de 2000. 
en los inversores, que no encuentran la seguridad jurídica necesaria para operar con normalidad en el país andino.

\section{III.2. La vertiente de las «comunidades de asuntos politicos»}

En la vertiente de las «comunidades de asuntos políticos» existía una verdadera amalgama de ideas y alternativas sobre cómo afrontar el problema del narcotráfico y sobre cuál era la mejor estrategia para poner fin al conflicto armado. A grandes rasgos, se pueden diferenciar cuatro grupos de propuestas para hacer frente a estos problemas: 1) incrementar la ayuda antinarcóticos a Colombia; 2) seguir con los niveles actuales de ayuda; 3 ) acabar con la ayuda a los militares; 4) dar un giro en la política hacia Colombia e incluir una visión más amplia.

\section{III.2.1. Incrementar la ayuda antinarcóticos}

Un primer grupo de soluciones eran las propuestas por analistas que consideraban que los esfuerzos en la lucha antinarcóticos debían seguir centrados en la reducción de la oferta, y que se oponían al proceso de paz colombiano sin que antes se produjera un sustancial debilitamiento de las FARC y el ELN. En su opinión, Pastrana había ya hecho demasiadas concesiones a las FARC, en especial al haber permitido que actuaran libremente en la zona desmilitarizada. Para ellos resultaba alarmante la falta de presencia del Estado colombiano en el sur de Colombia, en las provincias de Putumayo y Caquetá, donde se había disparado la producción de hoja de coca y las FARC se habían hecho fuertes gracias al dinero obtenido por su participación en el tráfico de drogas. Esta situación se había producido en su opinión por la debilidad del Ejército colombiano.

Estas ideas circulaban fundamentalmente entre los analistas del Departamento de Estado, del Departamento de Defensa y entre los sectores republicanos más conservadores. En su opinión, el problema del consumo de drogas en los EE.UU. viene motivado fundamentalmente por la llegada de drogas de los países andinos. Consideran que los EE.UU. están haciendo un buen trabajo, pero que se ven desbordados en sus esfuerzos y que era preciso un fuerte incremento en las ayudas a Colombia.

Su estrategia consistía en la reducción de la producción en los países de origen mediante la erradicación de cultivos y la incautación de la droga en tránsito. Consideraban que mediante estos métodos en los países productores de hoja de coca y amapola, los precios en los EE.UU. subirán lo suficiente como para desanimar a los consumidores. Ponían como ejemplo del éxito de su estrategia las políticas llevadas a cabo en Bolivia y Perú, donde con estas recetas se lograron reducciones muy significativas. Por ello, consideraban que el nuevo boom de la droga en Colombia se había producido no 
por el fracaso de estas medidas, sino porque el control de las guerrillas de amplias zonas permite a los narcotraficantes campar a sus anchas.

Dentro de este grupo existían discrepancias sobre si centrar la ayuda en los militares o en la policía colombiana. Los partidarios de dar la ayuda a los militares consideraban que, sin la ayuda del Ejército colombiano, resultaría imposible luchar contra el narcotráfico en las zonas controladas por la guerrilla. A su vez, este grupo se encontraba dividido. Por un lado, estaban los analistas que sugerían que la ayuda a los militares debía darse únicamente para labores de la lucha antinarcóticos. El apoyo estaría basado principalmente en helicópteros y radares para mejorar la erradicación y la interceptación. Otros analistas preferían que la ayuda se destinara tanto a ese propósito, como a la lucha contrainsurgente. Por esta razón, solicitaban que se incrementaran las ayudas para equipos, pero también las destinadas al entrenamiento de unidades de infantería, teóricamente antinarcóticos, y a la mejora de los servicios de inteligencia. Pretendían así poner fin a las continuas derrotas sufridas por el Ejército a manos de la guerrilla. Estas estrategias servirían no sólo para debilitar financieramente a la guerrilla, sino para justificar de forma encubierta el aumento en la ayuda a los militares colombianos, bajo la suposición de que sólo la iban a dedicar a la lucha antinarcóticos. Dichos analistas consideran que la falta de éxito del Ejército colombiano se debe al mal equipamiento de sus tropas y a las deficiencias de los servicios de inteligencia. En su opinión, los 3.000 millones de dólares anuales que el Gobierno colombiano destinaba a sus fuerzas de seguridad eran insuficientes para hacer frente a los grupos guerrilleros. Pese a defender esta dualidad encubierta, se negaban a la participación directa en los combates de las tropas estadounidenses (Sefarino, 1999: 18). Dada la participación de las FARC en el tráfico de drogas, la línea entre contrainsurgencia y lucha contra el narcotráfico había quedado tan difusa que la estrategia de este grupo sería poner el énfasis en la ayuda antinarcóticos, sin duda un tema mucho menos sensible para el Congreso y la opinión pública que la ayuda directa contra la guerrilla.

Por su parte, los defensores de la ayuda centrada en la policía, capitaneados por el republicano Benjamín Gilman, apuntaban que las fuerzas policiales estaban haciendo una gran labor y que sus unidades no estaban involucradas, al contrario que el Ejército, en violaciones de los derechos humanos.

\section{III.2.2. Continuar la ayuda en los niveles actuales}

Pese a ser conscientes del deterioro de la situación colombiana, este grupo de analistas estimaba que el incremento de la ayuda a Colombia en 1998 y 1999 fue un factor favorable para que la guerrilla reanudara las conversaciones con el Gobierno de Pastrana. Sin embargo, en su opinión, el aumento de la ayuda a niveles superiores podría convertirse en un argumento utilizado por la guerrilla para culpar a los EE.UU. de no querer la vía de la negociación y sí una solución militar al conflicto (Sefarino, 1999: 19). 
Argumentaban que los niveles de entonces permitirían un equilibrio entre la lucha contra el narcotráfico y la continuidad del proceso de paz. Según este razonamiento, Washington debía apoyar el proceso de paz, incluso si a corto plazo no se lograban resultados (Sefarino, 1999: 17). Por ello se pretendía seguir con los niveles de ayuda actuales y centrarlos en la Policía Nacional colombiana.

III.2.3. Partidarios de acabar con la ayuda a los militares

En clara oposición con el primer grupo estaban aquellos analistas que consideraban que, dada la oposición del Ejército colombiano al proceso de paz, destinar ayuda a los militares sólo empeoraría las cosas y desacreditaría a los EE.UU. como mediador en el conflicto (Sefarino, 1999: 20).

\section{III.2.4. Restricciones a la ayuda}

A caballo entre estos dos grupos estaban situados aquellos analistas que, independientemente de que se incrementara o no la ayuda, querían imponer más restricciones sobre su eventual concesión. En concreto, pedían que la ayuda no se destinara a unidades de las fuerzas de seguridad con vínculos con los paramilitares y exigían mayores esfuerzos del Gobierno colombiano para desmantelar a estos grupos, a los que consideran como uno de los principales obstáculos para el proceso de paz y para los problemas de Colombia (Sefarino, 1999: 19).

III.2.5. Partidarios de una política exterior hacia Colombia con miras más amplias

Este grupo, sin duda el más diverso en sus planteamientos, incluía analistas de círculos demócratas y académicos progresistas, que solicitaban una visión más global de los problemas de Colombia.

En su opinión, la violencia armada y la droga son problemas provocados en gran parte por la debilidad socioeconómica e institucional de Colombia. Por ello, propugnaban una mayor ayuda de los EE.UU. y de los organismos internacionales para resolver los problemas económicos, políticos y sociales del país andino. Estos analistas destacaban también el fracaso de las políticas de incautación y erradicación de cultivos, a las que responsabilizan de haber provocado que muchos campesinos abandonaran las tierras y pasaran a nutrir las filas de las guerrillas o de los paramilitares. Dado el fracaso de las estrategias, proponían que la lucha antinarcóticos fuese un elemento secundario en la política hacia Colombia, y que primaran los programas de cultivos alternativos 
o de reforma agraria, la reforma del sistema judicial, la ayuda a los desplazados y el apoyo al proceso de paz (Sefarino, 1999: 21).

Paralelamente, defendían que la lucha contra la droga debía estar fundamentalmente basada en el tratamiento doméstico en los EE.UU. En su opinión, aunque la producción se eliminara en Colombia, mientras no se redujera la demanda en los EE.UU., la droga se movería a otros lugares, tal como sucedió con el trasvase de la producción de hoja de coca de Bolivia y Perú a Colombia.

Estos grupos cuestionaban la lógica de que la represión en los países productores desalentaría el consumo en los EE.UU. Según Peter Reuter, un antiguo economista de la Rand Corporation, incluso si se doblara el precio de exportación de la cocaína, ello incrementaría el precio en la calle en no más de un 5 por ciento, lo que tendría un mínimo efecto en su consumo (Youngers, 1997).

Como respaldo a sus argumentos, señalaban un estudio elaborado en 1994 por Rand Corporation y financiado en parte por el Departamento de Defensa de los EE.UU. El estudio de este prestigioso think-tank concluía que, a la hora de reducir el consumo de cocaína en los EE.UU., invertir dinero en combatir la demanda con programas de tratamiento de toxicómanos resultaba 23 veces más eficaz que invertirlo en estrategias de reducción por la vía de la represión en los países productores.

Por último, estos analistas alertaban del peligro de una mayor participación de Washington en el conflicto colombiano, lo que podría llevar a los EE.UU. a un nuevo Vietnam, y tendría fuertes repercusiones en los derechos humanos en Colombia.

\section{III.3. La corriente de la política}

Junto a los problemas señalados con anterioridad, los cambios en la opinión pública y las campañas de los grupos de presión jugaron un papel fundamental a la hora de lograr la inclusión del paquete de ayuda a Colombia en la agenda del Ejecutivo estadounidense.

\section{III.3.1. Cambios en la opinión pública}

La génesis del paquete de ayuda de 1.300 millones de dólares a Colombia y a la región andina volvió a poner de manifiesto la importancia de la opinión pública estadounidense en la guerra contra las drogas ante la proximidad de un proceso electoral. Al igual que sucediera en vísperas de las elecciones presidenciales de noviembre de 1996, en la decisión de Clinton de incluir la ayuda en su agenda política jugaron un papel relevante los cambios que se produjeron entre la opinión pública.

Tal como señala el reportaje de investigación del 3 de abril del 2000 de la revista Newsweek, The Other Drug War, en septiembre de 1999 una encuesta llevada a cabo 
por el demócrata Mark Mellman puso de manifiesto que los estadounidenses percibían que el uso de estupefacientes se estaba incrementando en los EE.UU. Es más, la gente tendían a culpar a los demócratas de no estar haciendo lo suficiente y de ser demasiado blandos en la lucha contra las drogas. Según la encuesta, el 56 por ciento del electorado apoyaría un incremento de 2.000 millones de dólares para labores de erradicación e incautación de producción de la droga. Ante este hecho, y tratándose de un año electoral, los demócratas no podían dejar que los republicanos les achacaran la falta de responsabilidad en la lucha contra la droga y que ello les perjudicara durante la campaña electoral (Isikoff y Vistica, 2001).

Ya en los presupuestos del otoño anterior, los republicanos habían logrado la aprobación de 287 millones de dólares de ayuda antinarcóticos y de apoyo a los militares colombianos. Nuevamente, en el presupuesto de 1999 los republicanos presentaron su propio plan en el Senado, que aunque no se sometió a votación, sirvió para poner más presión sobre el Ejecutivo y sobre los demócratas ${ }^{16}$.

A estos datos se unieron las encuestas realizadas por Gallup entre noviembre de 1998 y enero de 1999, encargadas por la Office of National Drug Control Policy. El 53 por ciento de los estadounidenses manifestaban que su preocupación sobre el consumo de drogas había aumentado en los últimos 5 años. Tan solo un 3 por ciento admitía que había descendido, mientras que la preocupación se había mantenido estable en un 44 por ciento de los encuestados. Es más, 8 de cada 10 personas entrevistadas se mostraron de acuerdo en que debería emplearse más dinero en parar la droga en los países de origen antes de su llegada a los EE.UU. La encuesta también mostraba que los estadounidenses estaban divididos con respecto a si el tratamiento y la rehabilitación son los métodos más efectivos para aquellos adictos a las drogas. Un 50 por ciento piensa que el tratamiento es efectivo, mientras que el 42 por ciento se manifestó en contra ${ }^{17}$.

\section{III.3.2. Grupos de presión}

Ante el deterioro de la situación en Colombia, comenzaron a intensificarse las campañas a favor de la ayuda de los grupos de presión con inversiones en Colombia y de aquellas empresas que podrían beneficiarse de la aprobación de un paquete con un amplio contenido militar.

Las más poderosas empresas multinacionales estadounidenses con intereses en Colombia, agrupadas desde 1996 en el denominado U.S.-Colombia Business Partnership, que representa entre otros a Occidental Petroleum, Enron, BP-Amoco y Texaco, incrementaron sus protestas ante el Ejecutivo y el Congreso por la falta de protección

16. Tim Golden y Steven Lee Myers. U.S. Plans Big Aid Package to Rally a Reeling Colombia. The New York Times, 15 de septiembre de 1999.

17. Office of National Drug Control Policy Consultation with America A Look at How Americans View the Country's Drug Problem, 22 de noviembre de 1999. 
efectiva de sus inversiones. La unanimidad de estas empresas en señalar el deterioro de sus intereses en Colombia acrecentó sin duda la receptividad del Ejecutivo para incrementar la ayuda a los militares colombianos ${ }^{18}$.

Además, y según Newsweek, Lockheed Martin, los fabricantes de los aviones con radar P-3, utilizados para interceptar la droga en tránsito, financió la encuesta de Mellman. Según el Newsweek, esta empresa ha estado presionando para lograr fuertes incrementos en el gasto en tecnologías para interceptar la droga. El paquete de ayuda acabó incluyendo 343 millones de dólares para este fin (Isikoff y Vistica, 2001). Según las investigaciones del Center for Responsive Politics de Washington, las donaciones de «dinero blando» de esta empresa a republicanos y demócratas alcanzaron entre 1999 y 2000 la cifra de 1,15 millones de dólares.

Por su parte, el Gobierno colombiano, ante el deterioro del proceso de paz, contrató los servicios de la firma de abogados Akim Gump para articular y coordinar, junto a su embajada en Washington, la solicitud de más ayuda económica y militar a los EE.UU. Resultó de suma importancia la mejora de la imagen que logró Pastrana en Washington logrando contrarrestar la desconfianza generada durante el mandato de Ernesto Samper. Colombia volvió a ser certificada y las Fuerzas Armadas colombianas mejoraron su reputación respecto a las violaciones de los derechos humanos.

Junto a estos intereses, cabe destacar el papel desempeñado por las compañías de fabricantes de helicópteros. Estas empresas vieron en un hipotético nuevo paquete de ayuda a Colombia la gran oportunidad para la venta de sus productos en América Latina. Tanto Textron, con sede en Texas, fabricantes del helicóptero Bell Huey, y United Technologies Corporporation, con sede en Connecticut, cuya división Sikorsky Aircraft construye los Blackhawk, llevaron a cabo agresivas campañas que llegaron a incluir paseos en helicópteros de congresistas. Tal como muestran los registros federales electorales, ambas compañías realizaron importantes contribuciones a las campañas electorales, tanto de los demócratas como de los republicanos, a las que donaron 1,25 millones de dólares entre 1997 y 1999. Precisamente en 1999, United Technologies realizó un cambio estratégico y, habiendo favorecido con anterioridad a los republicanos, pasó a destinar dos tercios de su «dinero blando» 19 a los demócratas, depositando cuatro cheques, cuya suma ascendía a 125.000 dólares, en varios comités demócratas. La mayoría del dinero, 75.000 dólares, fue depositada en un solo día, el 31 de diciembre de 1999, 11 días antes del anuncio del paquete de ayuda a Colombia (Isikoff y Vistica, 2001).

Según el periódico The New York Times, en base a los datos de las investigaciones de la empresa Campaign Study Group, en los ciclos electorales de 1996 y 1998, Textron y sus empleados donaron a los republicanos (que controlaban el Congreso) 551.816 dólares y 364.420 a los demócratas. Además de las donaciones, estas empresas habían

18. Sam Loewenberg. Big Guns Back Aid to Colombia: Well-Financed U.S. Lobby Seeks Relief From Drug Wars. Legal Times, 21 de febrero de 2000.

19. El dinero blando son aquellas donaciones sin restricciones entregadas por empresas o individuos a los partidos políticos. 
venido celebrando encuentros para persuadir sobre la urgencia en hacer frente a los problemas de Colombia. Cuando en el otoño de 1999 se empezó a diseñar el borrador de lo que sería el paquete de ayudas, los encargados de esta labor barajaban tres opciones: una en la que no se incluiría ningún Blackhawk, y otras dos en las que en los últimos años del plan, una vez que los militares colombianos hubieran logrado algún tipo de avance, se incluirían 45 ó 60. Sin embargo, justo antes de las Navidades de 1999, funcionarios en la Casa Blanca decidieron incluir 30 Blackhawks para ser adquiridos tan pronto fuera posible, y reducir a la mitad las cantidades previstas para algunos de los programas de desarrollo20.

En contraposición con estas campañas en favor de la ayuda, los grupos de defensores de los derechos humanos, en especial American Human Rights Watch y Amnistía Internacional, con el apoyo de determinados congresistas demócratas como Nancy Pelosi, David Obey o Patrick Leahy, presionaron en la dirección opuesta. Sus informes anuales y briefings, que fueron ampliamente difundidos, alertaron sobre los efectos negativos que un paquete con un alto componente militar tendría en los derechos humanos en Colombia. También dieron cuenta de la precaria situación de los desplazados por la guerra y las fumigaciones, y de los demostrados vínculos de ciertas unidades del Ejército con los paramilitares.

Sorprendió la falta de apoyo a estos grupos de congresistas como el senador Christopher J. Dodd, miembro del Comité de Relaciones Internacionales de la Cámara de Representantes, y del representante Sam Gejdenson, miembro del Subcomité de Relaciones Exteriores sobre Narcóticos del Senado. Ambos políticos se convirtieron en defensores a ultranza del paquete de ayuda y en concreto de la inclusión de los Blackhawks. En el pasado, los dos se habían consagrado como paladines en la defensa de los derechos humanos y se habían opuesto de forma rotunda al envío de ayuda militar a América Latina, especialmente durante los conflictos armados de los años 80 en Centroamérica. A nadie escapa el hecho de que United Technologies tiene su sede en Connecticut, y de que la compañía había venido realizando importantes contribuciones a sus campañas electorales. Según el Center for Responsive Politics, en el período 1997-2000, Sikorsky donó a Gejdenson 19.000 dólares, mientras que Dodd recibió 33.200 de la misma compañía ${ }^{21}$.

Carlos M. Salinas, director del programa de Amnistía Internacional en América Latina, reconoció sentirse muy decepcionado con la actuación de Gjedenson y Dodd, especialmente dada su experiencia sobre América Central en los años 8022.

20. Tim Golden. U.S.: Colombia and Copters and Clash Over Choice. The New York Times, 6 de marzo de 2000.

21. Sam Loewenberg. Big Guns Back Aid to Colombia: Well-Financed U.S. Lobby Seeks Relief From Drug Wars. Legal Times, 21 de febrero de 2000.

22. Tim Golden. U.S.: Colombia and Copters and Clash Over Choice. The New York Times, 6 de marzo de 2000. 


\section{III.4. Cómo y cuándo se produjo la conjunción de las tres corrientes}

Tal como se ha señalado anteriormente, en la primera mitad de 1999 los problemas de Colombia se incrementaron de forma notable. El nuevo boom de la droga, la severidad de la crisis económica, política y social, el brutal asesinato de tres defensores de los derechos humanos en marzo, la muerte de cinco americanos al estrellarse un avión espía estadounidense en la región de Putumayo y la falta de progresos en el proceso de paz, acabaron por incrementar la atención de Clinton y la secretaria de Estado Madeleine K. Albright hacia los problemas de Colombia. Estos factores, unidos a los cambios en la opinión pública, a las campañas de los grupos de presión y a la proximidad de un proceso electoral llevaron al Ejecutivo estadounidense a la conclusión de que no bastaba con lo que se estaba haciendo hasta la fecha, y que se necesitaba un giro importante en la política exterior hacia Colombia. Fue así como en el otoño de 1999 las tres corrientes mencionadas anteriormente coincidieron y abrieron la puerta para que se produjera un cambio. Dicha oportunidad fue aprovechada por determinados emprendedores políticos, que pusieron en marcha toda su maquinaria, tiempo, energía, reputación y dinero para lograr que un amplio paquete de ayuda, fundamentalmente militar, fuera incluido en la agenda del Ejecutivo.

Pese a que en el verano de 1999 Clinton estaba mucho más preocupado por los problemas de Colombia, para que finalmente tomara la decisión de apoyar sin reservas un plan de ayuda se tuvo que dar el clima adecuado. El concepto de narcoguerrilla de McCaffrey, el Plan Colombia de Pastrana, unido al hecho de la mejora de la imagen de los militares colombianos y a la certificación en los dos últimos años del país andino favorecieron dicho clima.

En julio de 1999, McCaffrey, que se encontraba cada vez más presionado por la falta de resultados en la lucha contra las drogas, alertó en diferentes encuentros de que la colaboración entre guerrilla y narcotraficantes había producido una «explosión» de los cultivos de coca en el sur de Colombia. El zar antidrogas transmitió a Clinton que si no se tomaban cartas en el asunto, sería tal el flujo de cocaína que iba entrar en los EE.UU. que la gente le responsabilizaría de no haber actuado con diligencia para atajar el problema a tiempo (Isikoff y Vistica, 2000).

El 13 de julio McCaffrey escribió una carta a Madeleine K. Albright advirtiéndole de la deficiencias de las Fuerzas de Seguridad colombianas y de la necesidad de su mejora para hacer frente a la guerrilla en el sur de Colombia y del peligro de la expansión en la producción de hoja de coca y de la posición de las FARC23. Por ello, McCaffrey solicitó con urgencia un paquete de ayudas de 1.000 millones de dólares (Shifter, 2000: 54). De ellos, pedía que al menos 360 millones se destinaran para ayudar al Ejército

23. Douglas Farah. U.S. Ready to Boost Aid to Troubled Colombia. Washington Post Foreign Service Monday, 23 de agosto de 1999, p. A1. 
colombiano a recuperar el control en el sur de Colombia y 120 millones de dólares para interceptar la droga en tránsito24.

A comienzos de julio se dio también la mayor ofensiva de las FARC en 40 años, por la que el grupo guerrillero se hizo con el control de 15 pueblos, uno de ellos muy próximo a Bogotá (Isikoff, 1999). El Gobierno colombiano, ante la falta de avances en el proceso de paz, comenzó a presionar a Washington para lograr más apoyo financiero y ayuda militar.

En agosto, el subsecretario de Estado Thomas Pickering y McCaffrey viajaron a Colombia y sugirieron a Pastrana que, si se creaba un plan global para lograr la recuperación económica del país, mejorar las Fuerzas Armadas y luchar contra el narcotráfico, sería posible lograr un importante paquete de ayuda estadounidense para su país. Pastrana fue también advertido que si se hacía más concesiones a la guerrilla para romper el statu quo corría el riesgo de perder el apoyo de Washington ${ }^{25}$.

De esta forma, en pocos días se creó el Plan Colombia que, aunque fue presentado como un plan del Gobierno colombiano, en su mayor parte había sido redactado por funcionarios estadounidenses de alto rango (Shifter, 2000: 54). La creación del Plan Colombia fue fundamental para abonar el terreno de cara a la formulación del paquete de ayudas. Su fachada de plan integral de solución a los problemas de Colombia haría más fácil articular y justificar ante la opinión pública y el Congreso un mayor compromiso de Washington con la situación en el país andino. Este hecho permitía además esquivar aquellas opciones de los analistas estadounidenses que solicitaban un enfoque más amplio en las relaciones bilaterales con Colombia, y abría la puerta para que la aportación de Washington al Plan Colombia se centrase en sus aspectos militares.

El Plan Colombia, presentado por Pastrana el 17 de septiembre de 1999, venía a ser una especie de «Plan Marshall» de 7.500 millones de dólares, a desarrollar en tres años y centrado en cinco puntos estratégicos: el proceso de paz, la economía colombiana, el desarrollo social y democrático, la lucha contra el narcotráfico, la reforma del sistema de justicia y la protección de los derechos humanos. De la suma total, 4.000 millones de dólares serían aportados por Colombia, y el resto vendría de contribuciones de la comunidad internacional y de instituciones financieras multilaterales.

El 20 de septiembre Pastrana visitó Washington para lograr que los EE.UU. contribuyeran con al menos 1.500 millones de dólares en ayuda directa para la implementación de «su plan». En su visita logró una respuesta favorable de Clinton, del speaker de la Cámara, el republicano J. Dennis Hastert, y del líder de la Mayoría en el Senado, el republicano Trent $\operatorname{Lot}^{26}$.

24. Tim Golden y Steven Lee Myers. U.S. Plans Big Aid Package to Rally a Reeling Colombia. The New York Times, 15 de septiembre de 1999.

25. Douglas Farah. U.S. Ready to Boost Aid to Troubled Colombia. Washington Post Foreign Service Monday, 23 de agosto de 1999, p. A1.

26. Colombian President's Aid Request Gets Favorable Response on Hill. CQ Weekly, 25 de septiembre de 1999. 
Solo faltaba diseñar con detalle los componentes del paquete de ayudas y que éste fuera introducido por el Ejecutivo en el Congreso. Si en un principio se pensó incluirlo en el presupuesto regular, el agitado y controvertido clima que se generó en torno al debate presupuestario de ese año desalentó a Clinton, que prefirió esperar al presupuesto extraordinario para no hacer peligrar la ayuda.

Tal como se vio en el presupuesto regular, un paquete de ayudas exterior de semejante envergadura no sólo necesita de una estrecha colaboración entre el Ejecutivo y los principales líderes del Congreso, sino que además requiere que el presidente lo solicite y lo respalde. Prueba de ello fue el fracaso de varios republicanos, que intentaron introducir su propio paquete de ayudas a Colombia. Esta propuesta, redactada por Paul Coverdell, R-Ga., Mike DeWine, R-Ohio, Charles Grassley, R-Iowa, no llegó a ser ni siquiera votada por el Comité de Relaciones Internacionales del Senado ${ }^{27}$, aunque sirvió para añadir más presión al Ejecutivo. Estos senadores propusieron un plan a tres años de 1.600 millones de dólares para la región andina, de los cuales 1.200 irían destinados a Colombia 28 .

\section{LA PROPUESTA DE CLINTON Y SU PASO POR EL CONGRESO}

El 12 de enero del 2000, Clinton anunció que sometería al congreso un paquete de ayuda antinarcóticos de 1.273 millones de dólares en el suplemento de emergencia del 2000, como apoyo al Plan Colombia de Pastrana y a los países andinos. El plan de Clinton incluía 1.025 millones de dólares para Colombia, 77 millones para el resto de los países andinos, 115,7 millones de ayuda a las agencias estadounidenses y 55 millones clasificados. Si a esta cifra se le añadían los 300 millones ya presupuestados para los años fiscales 2000 y 2001, la cifra ascendía a 1.300 millones de dólares. La propuesta coincidió con el anuncio por parte del zar antidrogas de nuevos y alarmantes datos de los servicios de inteligencia estadounidenses sobre el gran aumento en la producción de hoja de coca y amapola en Colombia.

La ayuda constaba de cuatro componentes fundamentales ${ }^{29}$ (ver Gráfico VI):

1) Ayuda a las Fuerzas Armadas de Colombia. La mayor partida presupuestaria (691,6 millones de dólares, el 67 por ciento del total) estaba destinada a los militares colombianos para que llevasen a cabo el denominado «empuje en el sur de Colombia», en las zonas de cultivo de hoja de coca de Putumayo y

27. President of Colombia Comes Calling in Search of More Aid. CQ Daily Monitor, 27 de enero de 2000.

28. Karen DeYoung. U.S. Plans Big Boost In Aid to Colombia. The Washington Post, 8 de enero de 2000.

29. Fact Sheet: Colombia Assistance Package. The White House (Grand Canyon, Arizona), 11 de enero de 2000. 
Caquetá controladas por las FARC. Los fondos serían empleados en el entrenamiento de batallones antinarcóticos, en la compra de 30 Blackhawks y 33 helicópteros Huey y en otras actividades que les permitieran hacer frente a las FARC mientras se realizaran las tareas antinarcóticos.

2) Ayuda a la Policía Nacional colombiana. A este cuerpo le serían asignados 109,2 millones de dólares (el 10,6 por ciento del total). Mediante la adquisición de nuevos radares y aviones y la mejora de los ya existentes, se pretendía aumentar la capacidad de este cuerpo para interceptar cargamentos de droga. Además, se intentaría mejorar su capacidad de erradicación de cultivos mediante la compra de nuevos equipos.

3) Ayuda para programas de desarrollo alternativo y a los desplazados por el conflicto. El paquete preveía un total de 106,5 millones de dólares (el 10,3 por ciento del total) para aquellos campesinos colombianos que abandonaran sus cultivos ilícitos y los sustituyeran por cultivos alternativos. También se preveían 39,5 millones de dólares (3 por ciento del total) para los desplazados por el conflicto.

4) Ayuda para mejorar la gobernabilidad. En esta categoría se incluían 15 millones de dólares para la defensa de los derechos humanos (1,46 por ciento del total), 21 millones para la reforma judicial ( 2 por ciento del total), 41,5 millones para la mejora del Estado de derecho (4 por ciento de total), y finalmente se destinaba 1 millón de dólares para el apoyo al proceso de paz $(0,09$ por ciento del total).

\section{GRÁFICO VI}

Propuesta original del EjeCUTIVO: DISTRIBUCiÓN DE LA AYUdA A COLOMBIA EN MILLONES
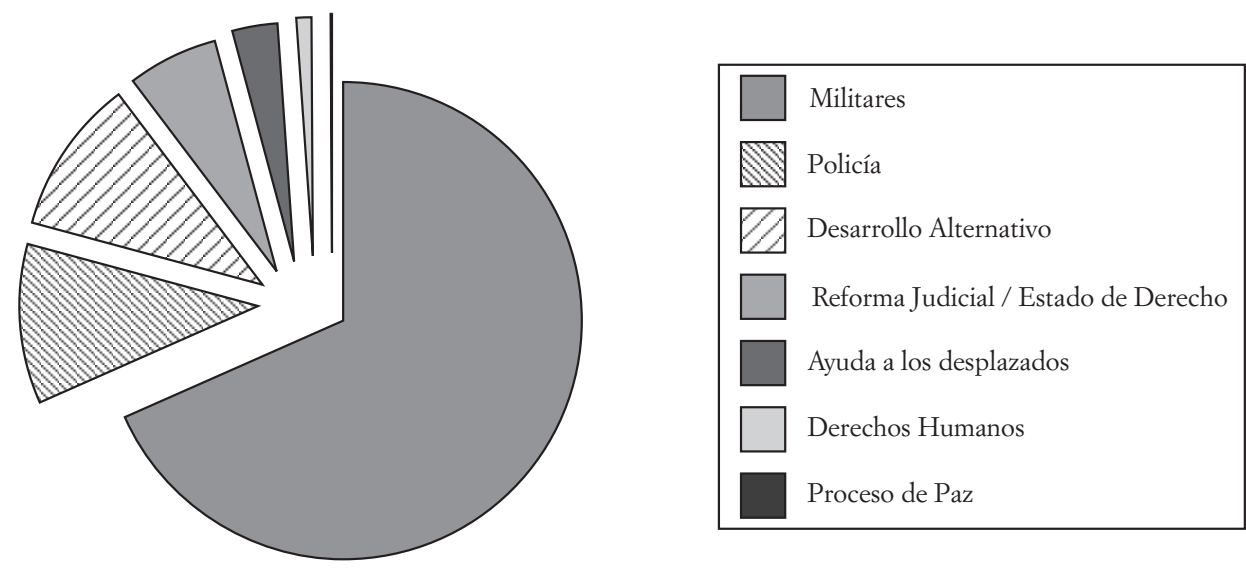

Fuente: Adam Isacson. The 2000-2001 Colombia Aid Package by the Numbers, Center for International Policy, 5 de julio de 2000. 
Sorprendió el alto componente bélico del paquete de ayudas. Sin duda, suponía un triunfo de los postulados más militaristas y de los grupos de presión con intereses económicos en Colombia o beneficiarios de posibles contratos armamentísticos, que fueron maquillados con fondos sociales. La mayoría de la ayuda, el 77,6 por ciento, estaba destinada a las fuerzas de seguridad colombianas. De ese porcentaje, se otorgaría a los militares el 67 por ciento, y el 10,6 por ciento se destinaría a la policía. Dentro de la ayuda militar, la partida más alta, 385 millones de dólares, se utilizaría para la compra de 30 Blackhawks. Los datos reflejaban un énfasis en la ayuda a los militares, bajo la justificación de que eran los únicos cuerpos capaces de conseguir que las guerrillas colombianas abandonaran las zonas de producción de hoja de coca.

\section{III.1. El paso de la propuesta del Ejecutivo por el Congreso}

El proyecto de ley que incluía el paquete de ayuda a Colombia, la H.R. 3908, 2000 Emergency Supplemental Appropriations Act, fue introducida en el Congreso en febrero. El anuncio de Bill Clinton recibió el apoyo inmediato tanto del speaker de la Cámara de Representantes, el republicano Dennis Hastert, como del líder de la Mayoría en el Senado, el republicano Trent Lott.

Hastert convirtió el paquete de ayuda en una de sus principales prioridades legislativas y enfatizó la necesidad de hacer frente al nuevo boom de la droga, antes de que fuera demasiado tarde para el Gobierno colombiano y para los hijos de los estadounidenses, que a su modo de ver se convertían en las primeras víctimas de tan sofisticado narcoterrorismo.

El 9 de marzo del 2000, el Comité de Apropiaciones de la Cámara de Representantes enmendó y votó su versión del paquete de ayudas como una parte del Suplemento de Emergencia del 2000, que incluía, entre otros, fondos para sufragar las inundaciones en Carolina del Norte y fondos para las tropas norteamericanas en Kosovo. La versión del Comité de Apropiaciones fue aprobada por un amplio margen: 33 votos a favor y 13 en contra. De los votos en contra, 11 fueron demócratas y 2 republicanos. La versión del Comité difirió muy poco de la propuesta original (ver Cuadro I) y sólo cabe mencionar que la ratio de ayuda a la policía sufrió un incremento del 5 por ciento, que les fue recortado a los militares (Isacson, 2000).

El paquete de ayudas fue considerado por la Cámara de Representantes los días 29 y 30 de marzo del 2000. La ley fue aprobada de forma bipartidista con 263 votos a favor y 146 en contra, con el apoyo de 64 por ciento de los republicanos y el 56 por ciento de los demócratas, lo cual puso de manifiesto divisiones en ambos partidos, en especial dentro de las filas demócratas. El debate en la Cámara reflejó las distintas visiones dentro de las comunidades de expertos sobre cómo solucionar el problema de la droga y el conflicto colombiano. 
Un importante grupo de demócratas encabezado por Patrik Leahy, Edward Kennedy, David Obey y Nancy Pelosi, presentó durante las deliberaciones una actitud claramente hostil a la propuesta de Clinton. Si bien este grupo no había logrado influir en el diseño de la ayuda, pusieron todo su empeño para que ésta fuera modificada a su paso por el Congreso. Sus protestas y exigencias se centraron en demandar la vinculación de la ayuda al respeto de los derechos humanos, en advertir del peligro que podría suponer una mayor participación de los EE.UU. en la guerra civil colombiana, y en la crítica al alto componente militar del paquete de ayudas. Por ello, demandaron que la mayor parte de los fondos fuera destinada a programas de desarrollo alternativo y a programas de desintoxicación y prevención en los EE.UU. Los informes anuales sobre Colombia de Amnistía Internacional y de American Human Rights Watch, que nuevamente alertaban sobre los vínculos entre las Fuerzas Armadas colombianas y los paramilitares, sirvieron para reforzar las posiciones de este grupo.

Junto a la influencia de este grupo, a las acciones de los grupos de presión, y al hecho de que se tratara de una propuesta del Ejecutivo, dos aspectos acabarían erosionando la oposición dentro de las filas demócratas. Por un lado, al tratarse de un año electoral, los demócratas no podían parecer blandos frente a sus constituyentes en el tema de la lucha contra la droga. Las enmiendas aprobadas por la Cámara de Representantes serían también de suma importancia para reducir sus reticencias.

Varios demócratas, que habían expresado previamente su desacuerdo con la ayuda, debido a su enorme componente militar, votaron finalmente a favor gracias a la aprobación de una enmienda por la cual se requería que el presidente de los EE.UU. certificara a Colombia por el compromiso de su Gobierno en la defensa de los derechos humanos (Vaicius, 2000).

Otra importante enmienda aprobada por la Cámara fue la que introdujo el representante demócrata Gene Taylor, que limitaba a 300 el número de personal militar estadounidense estacionado en Colombia. La enmienda redujo la preocupación de aquellos que temían un nuevo Vietnam.

El respaldo dentro de las filas republicanas fue mucho más unánime. En parte esto fue posible porque el Ejecutivo había trabajado codo con codo con los miembros del equipo de Hastert para asegurar la aprobación del paquete, y porque el plan de Clinton se asemejaba a la propuesta de ayuda que varios republicanos habían introducido sin éxito en el Senado en el otoño de 199930.

Las únicas trabas significativas a la ayuda en el lado republicano vinieron de varios miembros que, pese estar a favor de la ayuda a Colombia, se opusieron a ciertas partes del presupuesto suplementario por considerarlo un derroche para las arcas estatales.

Un grupo de republicanos encabezado por Benjamín Gilman se mostró disconforme por aumento de la ayuda a los militares en detrimento de la policía. A ojos de Gilman, la policía colombiana había liderado de manera exitosa la lucha contra el

30. Karen DeYoung. U.S. Plans Big Boost In Aid to Colombia. The Washington Post; Over $\$ 1$ Billion Pledged to Assist Drug War. Economy, 8 de enero de 2000. 
narcotráfico, y al contrario que los militares, contaban con personal lo suficientemente entrenado para pilotar los helicópteros. Pese a la inicial oposición, finalmente Gilman dio su respaldo a la ayuda y reconoció que, si bien la policía antinarcóticos debía ser la encargada de realizar la erradicación de cultivos de coca, era necesario que tuviera el apoyo del Ejército a la hora de desarrollar sus actividades en zonas controladas por la guerrilla (Isacson y Vaicius, 2000).

El paso de la ayuda por el Senado fue mucho más controvertido. La versión aprobada por parte del Comité de Apropiaciones de esta cámara supuso una variación considerable respecto a las partidas destinadas a los militares y a la defensa de los derechos humanos aprobadas por la Cámara de Representantes. Este hecho evidenció la creciente desconfianza de sus miembros hacia el «empuje en el sur de Colombia», por temor a que esta ayuda fuera a estar realmente destinada a la lucha contrainsurgente. Lo más sorprendente fue la eliminación de los 388 millones de dólares destinados a la compra de 30 helicópteros UH-60 Blackhawk, que fueron sustituidos por UH-1H «Super Huey», de mucho menor precio y calidad. También se destacó la incompatibilidad de la ayuda militar con la defensa de los derechos humanos. Como resultado, la dotación para la defensa de los derechos humanos se triplicó, pasando de los 15 millones de dólares de la propuesta original a 53,3 millones (Vaicius, 2000).

Gracias a la iniciativa del senador demócrata Patrick Leahy, se incorporó una enmienda por la que se condicionaba la entrega de la ayuda de los años fiscales 2000 y 2001 a la certificación por parte del Departamento de Estado de los EE.UU. de que los miembros de las Fuerzas Armadas colombianas sospechosos de haber cometido violaciones de los derechos humanos estaban siendo juzgados en cortes de justicia civil. Igualmente, se requería certificar que el Gobierno colombiano estaba haciendo todo lo posible para lograr el desmantelamiento de los grupos paramilitares. Otra enmienda limitó el número de personal militar destinado temporal o permanentemente a Colombia en 250 soldados. No obstante, el presidente se reservaría el derecho a requerir al Congreso el levantamiento de esta prohibición, o en caso de que las tropas estadounidenses se vieran atacadas, el número de efectivos podrían incrementarse durante el transcurso de 90 días (Sefarino, 2001: 9).

Los días 21 y 22 de junio, el paquete de ayudas fue sometido al plenario del Senado. Según la versión del Senado, el dinero a los militares colombianos se vio reducido a tan sólo 336 millones de dólares (350 millones menos que lo solicitado por Clinton), mientras que la partida para la defensa de los derechos humanos pasaba a ser 53,5 millones (el triple de lo establecido en la propuesta inicial) (ver Cuadro I).

Cabe mencionar el infructuoso intento del senador demócrata Paul Wellstone de que fuera aprobada una enmienda que pretendía que los fondos del «empuje en el sur de Colombia» se destinaran a programas de desintoxicación en los EE.UU. Por su parte, el senador Dodd, con el propósito de que se volvieran a incluir los Blackhawks, intentó que fuera aprobada una enmienda por la que se debían destinar no menos de 110 millones de dólares a la compra de helicópteros. Los modelos a adquirir se decidirían 
en consultas entre el Departamento de Defensa y las Fuerzas Armadas colombianas. La enmienda fue rechazada por tan solo cuatro votos (47-51) (Sefarino, 2001: 10).

Finalmente, el Comité de Conciliación de la Cámara de Representantes y del Senado acordó la versión final del paquete de ayudas. El montante definitivo sería de 1.320 millones de dólares, de los cuales 860,3 irían destinados a Colombia, y los fondos restantes a los países andinos. Si a la cantidad presupuestada para Colombia se le añadían los 330 millones previamente acordados, suponían un total de casi 1.200 millones de dólares en ayuda exterior en el transcurso de dos años (ver Gráfico I).

De los 860,3 millones de dólares destinados a apoyar al Plan Colombia, 519,2 (60 por ciento del total) serían finalmente destinados a los militares colombianos, mientras que la policía recibiría 123 millones de dólares (15 por ciento del total). La cantidad más elevada, 416,9 millones de dólares, se destinaría a la compra de helicópteros y al entrenamiento de batallones antinarcóticos (Sefarino, 2001: 11). Finalmente los militares colombianos recibirían 18 helicópteros Blackhawk y 42 Huey, mientras que a la Policía Nacional colombiana se le entregarían 12 Hueys y 2 Blackhawk (Vaicius, 2000). Pese a que se mantenía la cifra aprobada por el Senado para la defensa de los derechos humanos (el triple de la propuesta inicial de Clinton), la cifra destinada a desarrollo alternativo quedaba reducida a 68,5 millones de dólares, 38 millones menos que el paquete inicial.

CUADRO I

PARTE DEL PRESUPUESTO ADICIONAL DESTINADA A COLOMBIA EN MILLONES DE DÓLARES (excluyendo los 330 millones de dólares aprobados anteriormente)

\begin{tabular}{|l|c|c|c|c|}
\hline $\begin{array}{c}\text { DISTRIBUCIÓN } \\
\text { DE LA AYUDA } \\
\text { A COLOMBIA }\end{array}$ & $\begin{array}{c}\text { PROPUESTA } \\
\text { ORIGINAL }\end{array}$ & $\begin{array}{c}\text { CÁMARA DE } \\
\text { REPRESENTANTES }\end{array}$ & SENADO & $\begin{array}{c}\text { VERSIÓN } \\
\text { FINAL }\end{array}$ \\
\hline Militares & 691,6 & 630,7 & 336,0 & 519,2 \\
\hline Policía & 109,2 & 146,7 & 114,2 & 123,1 \\
\hline Desarrollo alternativo & 106,5 & 108,0 & 95,0 & 68,5 \\
\hline Ayuda a los desplazados & 39,5 & 39,5 & 39,5 & 37,5 \\
\hline Derechos humanos & 15,0 & 17,0 & 53,5 & 51,0 \\
\hline Reforma judicial & 21,0 & 23,5 & 18,0 & 13,0 \\
\hline Estado de derecho & 41,5 & 40,5 & 52,5 & 45,0 \\
\hline Proceso de Paz & 1,0 & 1,0 & 5,0 & 3,0 \\
\hline Total & $1.025,3$ & $1.006,9$ & 713,7 & 860,3 \\
\hline
\end{tabular}

Fuente: Adam Isacson. The 2000-2001 Colombia Aid Package by the Numbers. Center for International Policy, 5 de julio de 2000. 
Cabe destacar que las restricciones impuestas en el Senado referentes a los derechos humanos fueron debilitadas por una cláusula que permitiría al presidente omitirlas por motivos de seguridad nacional (Vaicius, 2000). La versión definitiva fue firmada por Clinton el 13 de julio de 2000.

\section{CONCLUSIONES}

La génesis y aprobación del paquete de ayudas de 1.300 millones de dólares de apoyo al Plan Colombia y a la región andina ponen de manifiesto importantes continuidades y nuevas dinámicas en la política exterior de los EE.UU. hacia América Latina.

Tras el final de la Guerra Fría la aprobación de fuertes sumas de ayuda exterior con un alto componente militar es una dura tarea que requiere de la articulación de nuevos enemigos externos y del contexto adecuado para evitar el recelo de la opinión pública y el Congreso. La promoción del concepto de narcoguerrilla sirvió para que determinados emprendedores políticos pudieran esquivar los recelos de muchos congresistas y para que la ayuda fuera aprobada de forma bipartita al ser presentada como un paquete antinarcóticos. El liderazgo republicano en el Congreso y McCaffrey fueron capaces de convencer a Clinton y hacer valer sus soluciones a los problemas de Colombia en concordancia con los intereses geopolíticos y económicos de los EE.UU. en el país andino y factores de tipo doméstico. Si bien la clase política estadounidense difiere sobre cuál debe ser el grado de injerencia en un conflicto armado fuera de sus fronteras, en líneas generales confluyen en la necesidad de centrar los esfuerzos de la lucha contra la droga en reprimir la oferta en los países productores, especialmente en un año electoral.

Pese al fracaso de las estrategias centradas en la represión de la oferta, en lugar de buscar soluciones domésticas para frenar la enorme demanda, Washington sigue culpando a los países latinoamericanos de las muertes de sus ciudadanos y criminalizando el consumo de estupefacientes. Una vez más, la aprobación de legislación antinarcóticos relevante coincidió con un cambio de Administración, lo que confirma que factores domésticos en los EE.UU. siguen condicionando la lucha antinarcóticos en la región andina y que la clase política estadounidense evita realizar un debate público profundo sobre el problema de la droga.

Pese a que numerosos estudios señalan a los programas de tratamiento de los toxicómanos y a la prevención como las formas más eficaces para reducir el consumo de droga, tan sólo algunos demócratas como Nancy Pelosi, David Obey o Patrick Leahy han intentado en los últimos años presionar para que la primacía de estas soluciones sean incluidas en las agendas políticas. Al igual que pasara con Ford y Carter, Clinton se negó a malgastar «capital político» en un asunto que suscita la reacción de los sectores más moralistas de los EE.UU. 
El caso de Colombia confirma la continuidad de los EE.UU. como principal estabilizador regional y cómo se sigue reservando el derecho a intervenir directa o indirectamente a través de ayuda militar en situaciones de inestabilidad. Si la guerra contra las drogas en los países productores se utiliza para evitar afrontar responsabilidades políticas domésticas, el concepto de narcoguerrilla sirve para justificar formas indirectas de lucha contra grupos insurgentes de izquierdas que van contra los intereses y principios defendidos por Washington. Así, el pretexto de la lucha contra las drogas permite erosionar tanto el recelo de los dirigentes y población latinoamericanos, como el temor de los miembros del Congreso y de la opinión pública estadounidense a un nuevo Vietnam. Los intereses geopolíticos de los EE.UU. se solaparon a partir de 1996 con el problema doméstico del consumo de droga y allanaron el camino a lo que ha sido el mayor paquete de ayudas a un país de América Latina desde el final de la Guerra Fría. El paquete de ayudas consolida la tendencia de la militarización de la guerra contra las drogas en América Latina y la intensificación de los lazos con los militares de los países de la región. El alto componente militar de la ayuda puso de manifiesto que la derrota o el debilitamiento sustancial de las FARC y el ELN sigue siendo una de las principales prioridades de la política exterior de Washington en América Latina y que la mejora de las capacidades de los militares colombianos representa una prioridad en sus relaciones con el país andino. Aunque el Gobierno estadounidense insista en la separación entre lucha antinarcóticos y lucha contra la guerrilla, en la práctica la ayuda y el entrenamiento serán empleados para ambos fines.

El caso analizado muestra además el importante papel que los grupos de interés con inversiones en Colombia o que pueden beneficiarse del componente militar de la ayuda exterior, llegan a jugar en un orden internacional en el que el interés nacional está más difuminado que durante la Guerra Fría.

\section{El futuro: consecuencias de la ayuda y nuevas sombras}

El alto componente militar de la aportación estadounidense acabó por hundir el ya debilitado proceso de paz de Andrés Pastrana y generó el recelo de la comunidad internacional hacia el Plan Colombia. La Unión Europea consideró el plan como excesivamente militarista y aunque finalmente se aprobaron 355 millones de dólares, esta cantidad se donó específicamente para el apoyo al proceso de paz. Como resultado, los 3.500 millones de dólares que el plan preveía como donaciones de la comunidad internacional se vieron reducidos a las contribuciones de España (100 millones de dólares) y a las aportaciones de los EE.UU. (1.223 millones de dólares) (Isacson, 2001). Lo que había sido anunciado como un plan integral acabó convirtiéndose en un plan de los EE.UU. con un contenido fundamentalmente militar. 
Si los éxitos en Bolivia y Perú supusieron un movimiento de la producción de estos países a Colombia, el incremento en la erradicación en Putumayo ha supuesto un incremento en la provincia vecina de Nariño y en zonas de Perú en las que la producción de coca había sido erradicada así como en la frontera de Colombia con Ecuador (Sharpe y Spencer, 2000).

La Administración de George W. Bush ha seguido hasta la fecha la escalada bélica iniciada por Clinton para fortalecer a los militares colombianos. El 9 de abril del 2001, Bush solicitó al Congreso la aprobación de 732 millones de dólares para la denominada «Iniciativa Andina Antinarcóticos». De esa cifra, 399 millones fueron requeridos para ser incorporados al Plan Colombia. Los 625 millones que finalmente fueron incluidos en el presupuesto regular del 2002 (alrededor de 380 millones de dólares presupuestados para Colombia) reflejaron la continuidad de las políticas militaristas y de represión de la oferta.

Si el concepto de narcoguerrilla abrió el camino para el comienzo del envío de importantes sumas, la lucha contra el terrorismo ha abierto la puerta para acabar con la ambigüedad entre ayuda destinada a la contrainsurgencia y ayuda destinada a la lucha contra el narcotráfico. Tras los acontecimientos del 11 de septiembre, Bush ha dado un paso más que su predecesor. Pese a que las FARC y el ELN no suponen una amenaza directa para los EE.UU., los dos grupos guerrilleros, junto con los paramilitares, han sido catalogados como grupos terroristas internacionales. Al concepto de narcoguerrilla se une ahora el del terrorismo internacional. Por primera vez desde el final de la Guerra Fría se ha difuminado la línea que separa la lucha contrainsurgente de la lucha contra la droga. Este hecho ha abierto la puerta para que ya no haga falta encubrir la lucha contrainsurgente y que abiertamente se solicite el dinero al Congreso para dicho fin.

En el presupuesto suplementario del 2002, además de dinero adicional, el Congreso aceptó la petición de Bush para que se autorizara la utilización de toda la ayuda aprobada para labores antinarcóticos en Colombia con objeto de apoyar una campaña unificada contra el tráfico de drogas, las actividades terroristas y otro tipo de amenazas para la seguridad nacional colombiana.

En la actualidad, Bush ha solicitado 538 millones de dólares adicionales en ayuda para Colombia para ser incluidos en el año fiscal el 2003, 98 de los cuales serían empleados para el entrenamiento de batallones que se encargarán de defender el oleoducto de Caño Limón de los ataques guerrilleros. Ese hecho supone un punto de inflexión muy importante con los años anteriores, ya que por primera vez se ha solicitado ayuda militar destinada a propósitos diferentes de la lucha antinarcóticos.

Las nuevas dinámicas de Washington, unidas a la línea dura mostrada por el nuevo presidente de Colombia Álvaro Uribe, dejan al país andino al borde de un recrudecimiento sustancial del conflicto armado. 
BORJA DÍAZ RIVILLAS

POLÍTICA EXTERIOR DE LOS EE.UU. HACIA COLOMBIA

\section{BibliografíA}

Bagley, M. Bruce y Walker O. Willian (eds.). Drug Trafficking in the Americas. University of Miami, North-South Center, 1994.

Bertram, Eva et al. Drug War Politics: the Price of Denial. Berkeley y Los Angeles, California: University of California Press, 1996.

CHERnICK, Marc. The Paramilitarizacion of the War in Colombia. NACLA Report on the Americas, marzo/abril 1998, vol. XXXI, n. ${ }^{\circ} 5$.

Doyle Kate e IsACSOn Adam. A New World Order?: U.S. Military Mission Grows in Latin America. NACLA Report on the Americas, noviembre/diciembre 2001, vol. 35, n. ${ }^{\circ} 3$.

IsACSON, Adam. The 2000-2001 Colombia Aid Package by the Numbers. Center for International Policy, 5 de julio, 2000.

- Intervención de Adam Isacson. Centro para las Políticas Internacionales, Escuela Superior de Administración Pública, Bogotá, Colombia, 16 de junio de 2001.

IsACSON, Adam y VAICIUS, Ingrid. «Plan Colombia»: The Debate in Congress. Center for International Policy, diciembre 2000.

IsIKoff, Michael y Hammer, Joshua. The Narco-Guerrilla War. Newsweek, 9 de agosto, 1999.

IsiKoff, Michael y Vistica Gregory. The Other Drug War. Newsweek, 3 de abril, 2000.

KeEn, Benjamin. A History of Latin America. New Jersey: Princeton University Press, 1996.

Kingdon, John. Agendas, Alternatives, and Public Policies. HarperCollins College Publishers, 1995.

LANCASTER, Carol. Transforming Foreign Aid: United States Assistance in the $21^{\text {st }}$ Century. Institute of International Economics, 2000.

McSherRY, J. P. Preserving Hegemony. National Security doctrine in the post-Cold War Era. NACLA, XXXIV (3), octubre 30-noviembre de 2000, pp. 26-34.

Sabatien, Paul. Theories of the Policy Process. Boulder: Westview Press, 1999.

Salazar, Ana María. Estado de Emergencia: El porqué del plan Colombia. Foreign Affairs en Español, primavera 2001.

Sefarino, Nina. Colombia: Conditions and U.S. Policy Options. Washington: Congressional Research Service, 7 de octubre, 1999.

- Colombia: Conditions and U.S. Policy Options. Washington: Congressional Research Service, 4 de mayo, 2000.

- Colombia: Plan Colombia Legislation and Assitance (FY2000-FY2001). Washington: Congressional Research Service, 5 de julio, 2001.

SHARPE, E. Kenneth y SPENCER, William. Refueling a Doomed War on Drugs: Flawed Policy Feeds Growing Conflict. NACLA Report on the Americas, noviembre-diciembre de 2000, vol. 34, n. $^{\circ} 3$.

SHIFTER, Michael. The United States and Colombia: Partners in Ambiguity. Current History, febrero de 2000, 99, pp. 51-54.

- Colombia on the Brink. Foreign Affairs, julio/agosto de 1999, pp. 14-20.

STEINER, Roberto. Hooked on Drugs: Colombian-US Relations. En Bulmer-ThOmas, V. y DuNKERLEY, J. (eds.). The United States and Latin America: The New Agenda. London: ILAS, 1999.

Thoumi, Francisco. Illegal Drugs in Colombia: From Illegal Economic Boom to Social Crisis. Latin American and Caribbean Center. Florida International University. Working Paper Series, agosto de 2001. 
VAICIUS, Ingrid. «El Plan Colombia»: el Debate en los EE.UU. Center for International Policy, agosto de 2000.

Youngers, Coletta. U.S. Entanglements in Colombia Continue. NACLA Report on the Americas, marzo-abril de 1998, 31 pp. 34-35.

- The Only War we've got: Drug Enforcement in Latin America. NACLA Report on the Americas, septiembre/octubre de 1997, vol. XXXI, n. ${ }^{\circ} 2$, 